\title{
The Performance of Airborne C-Band PolInSAR Data on Forest Growth Stage Types Classification
}

\author{
Qi Feng ${ }^{1}$, Liangjiang Zhou ${ }^{1, *}$, Erxue Chen ${ }^{2}$, Xingdong Liang ${ }^{1}$, Lei Zhao ${ }^{2}$ and Yu Zhou ${ }^{3}$ \\ 1 Sciences and Technology on Microwave Imaging Laboratory, Institute of Electronics, \\ Chinese Academy of Sciences, Beijing 100094, China; fengqi19872005@163.com (Q.F.); \\ xdliang@mail.ie.ac.cn (X.L.) \\ 2 Research Institute of Forest Resources Information Technique, Chinese Academy of Forestry, Beijing 100091, \\ China; chenerx@ifrit.ac.cn (E.C.); zhaoleiiam@126.com (L.Z.) \\ 3 Graduate School of Geography, Clark University, Worcester, MA 01610, USA; yuzhou2@clarku.edu \\ * Correspondence: ljzhou@mail.ie.ac.cn; Tel.: +86-10-5888-7636
}

Received: 20 June 2017; Accepted: 27 August 2017; Published: 14 September 2017

\begin{abstract}
In this paper, we propose a classification scheme for forest growth stage types and other cover types using a support vector machine (SVM) based on the Polarimetric SAR Interferometric (PolInSAR) data acquired by Chinese Multidimensional Space Joint-observation SAR (MSJosSAR) system. Firstly, polarimetric, texture, and coherence features were calculated from the PolInSAR data. Secondly, the capabilities of the polarimetric, texture, and coherence features in land use/cover classification were quantified independently through histograms. Following this, the polarimetric features were used for the classification of land use/cover types, followed by a combination of texture and coherence features. Finally, the three classification results were validated against test samples using the confusion matrix. It was shown that, with the integration of texture and coherence features, the producer's accuracy for afforested land, young forest land, medium forest land, and near-mature forest land improved by $6 \%, 31 \%, 11 \%$, and $6 \%$, respectively, compared with the former experiment using solely polarimetric features. Our study indicates that the forest and non-forest lands can be discriminated by the polarimetric features, which also play an important role in the separation between afforested land and other forest types as well as medium forest land and near-mature forest land. The texture features further discriminate afforested land and other forest types, while the coherence features obviously improved the separation of young forest land and medium forest land. This paper provides an effective way of identifying various land use/cover types, especially for distinguishing forest growth stages with SAR data. It would be of great interest in regions with frequent cloud coverage and limited optical data for the monitoring of land use/cover types.
\end{abstract}

Keywords: PolInSAR; forest types; polarimetric; texture; coherence

\section{Introduction}

Forests play an important role in carbon storage and carbon dynamic cycles [1]. Furthermore, forest plantations have significant effects on carbon uptake and climatic variations. The efforts in conserving forest ecosystems rely on knowledge of the plantations at different stages of growth, which is also a crucial indicator for the sustainable management and development of forests [2]. Therefore, it is necessary to specifically discriminate forest growth stages, which has been reported and evaluated using various remotely sensed datasets [3-5]. With the characteristics of cloud penetration and day/night acquisition, Synthetic Aperture Radar (SAR) data has been widely applied in forest classification. The SAR backscattering properties of forests vary with their physical features, such as forest species, height, and density [6]. Thus, SAR data can be used to distinguish forest from non-forest land [7-13] and to monitor forest growth/regrowth [14,15]. 
The potential of C-band SAR data in forest classification has been analyzed in previous studies, which demonstrated that conventional C-band SAR polarizations $\mathrm{HH}, \mathrm{HV}$, and VV provided a limited discrimination of tree species [16-18]. However, the polarization information provided by fully polarimetric SAR significantly improved forest type discrimination under both conditions of leaf-on and leaf-off [19]. Techniques based on the target decomposition theory and statistical properties of the backscattered signal constitute the primary approach for the radar polarimetric classifications, which are used mainly in Cloude-Pottier decomposition [20] and Freeman-Durden decomposition [21]. The Cloude-Pottier decomposition can draw three parameters (entropy, alpha, and anisotropy), which are each correlated with specific physical properties. The Freeman-Durden decomposition can determine the contribution of surface scattering, volume scattering, and the trunk-ground interaction scattering. Both target decomposition approaches are widely used in land use/cover classification, especially in forest classification $[19,22,23]$.

Although polarimetric information shows better performance in the classification of main land use/cover types [24-26], the capability for further classification of forest growth stages is limited due to the similar polarimetric behavior of different land use/cover types [15].

Interferometric observation is one of the promising methods of classification, with coherence being sensitive to the spatial heterogeneity of forest height and density, which are reflected in different forest growth stages [15]. Even small variations in the forest structure affect the position of the effective scattering center and subsequently result in different coherence values. Thus, interferometric coherence is suitable for classifying high biomass forest even at lower frequencies as it is hardly affected by any amplified saturation effects [15]. Ferro-Famil [27] proposed a Polarimetric SAR Interferometric (PolInSAR) algorithm to separate forests from manmade targets that were not aligned in the track direction. Ferro-Famil et al. [28] classified forest stand biomass into broad categories by reliably applying the k-means algorithm based on the statistics of an optimal coherence set. Lee et al. [15] evaluated the potential of combining polarimetric and interferometric classification approaches to classify forest types and growth stage using a k-means algorithm. The results showed that polarimetric information had little effect on forest classification, while the interferometry information plays an important role in the improvement of classification accuracy.

Forest classification accuracy can be improved by adopting texture information that exploited from multi-source remote-sensing data [29-31] or only SAR data. For instance, based on the Japanese Earth Resources Satellite-1 (JERS-1) SAR data, texture features were derived to refine the classification in the flooded forest class [9]. In a similar way, Advanced Land Observing Satellite Phased Array type L-band Synthetic Aperture Radar (ALOS PALSAR) and Radar Satellite-2 (RADARSAT-2) textures were used to classify a tropical moist region [32], with the results, compared to those of individual datasets, being considerably more accurate when datasets were combined.

Forest plantations are usually characterized by a single tree species and uniform distribution with a partially closed canopy in this research. This leads to similar scattering properties between different forest types [33], especially for the C-band SAR. Therefore, the forest type could not be accurately classified using the limited polarimetric SAR data [15]. The airborne PolInSAR data, including the polarimetric, interferometric, and texture features, are the advanced form of SAR data, which provides extremely abundant information for the classification of forest growth stages. In this study, polarimetric, texture, and coherence information were derived from PolInSAR data, before the capabilities of these features in distinguishing forest growth stages were analyzed through the histograms. Finally, a support vector machine (SVM) [34,35] was used for the classification of forest growth stages, with the results validated by indicators including overall accuracy, kappa coefficient, and producer's and user's accuracy. As the study mentioned above, we aimed to exploit the potential of PolInSAR data in order to accurately classify forest growth stages. 


\section{Test Site and Dataset}

\subsection{Test Site Description}

The test site is located in the Tianjin city of China (Figure 1a,b), with an area of $5.5 \mathrm{~km}^{2}$. Figure 1c showed the test site as obtained from Google Earth, while Figure 1d shows the Pauli RGB image derived from SAR data. The center coordinates of the test site are $40^{\circ} 2^{\prime} 10^{\prime \prime} \mathrm{N}, 117^{\circ} 42^{\prime} 26^{\prime \prime} \mathrm{E}$. The dominant land use/cover types include forest plantations, farmland, water, and buildings. The forest plantations are dominated by poplars (Populus L.), including afforested land, young forest, medium forest, and near-mature forest. The test site is mostly flat and its average elevation is $20 \mathrm{~m}$.
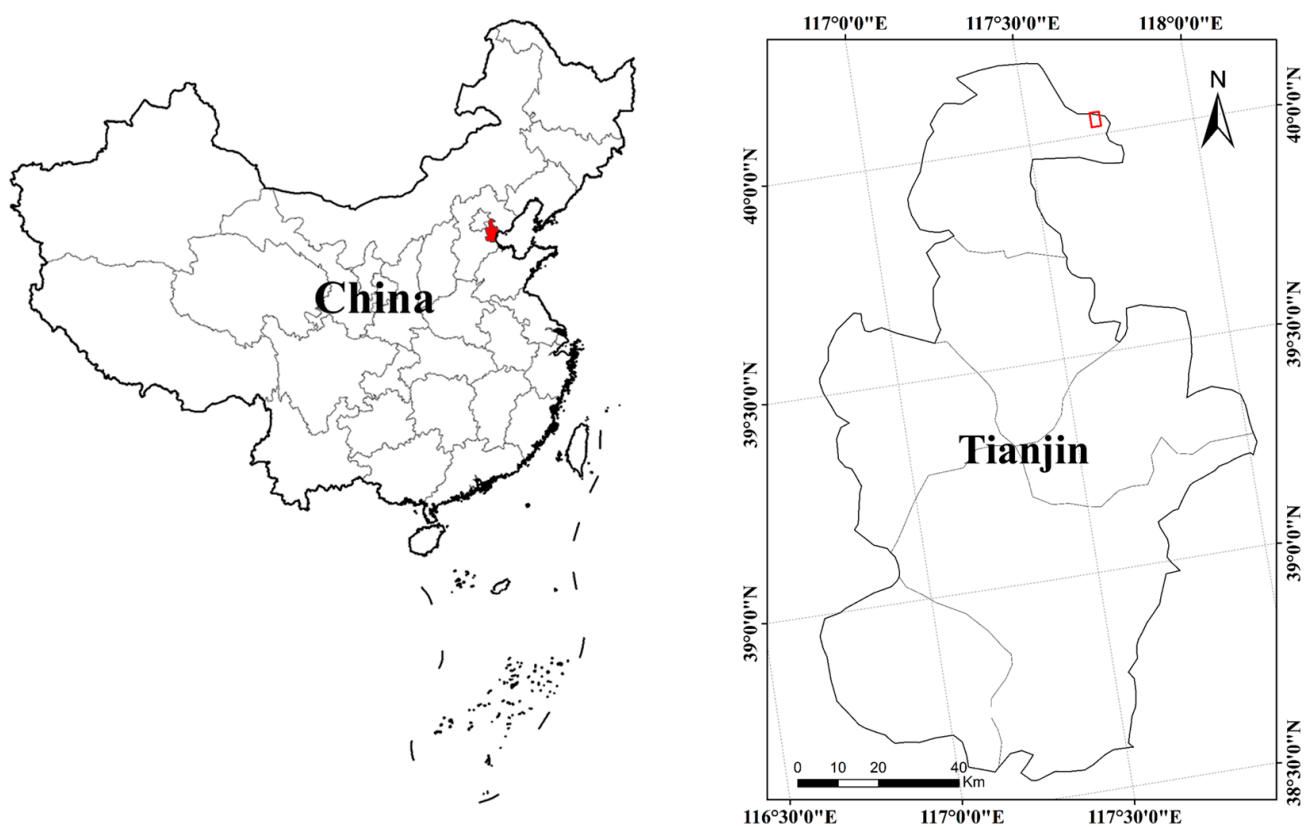

(a)

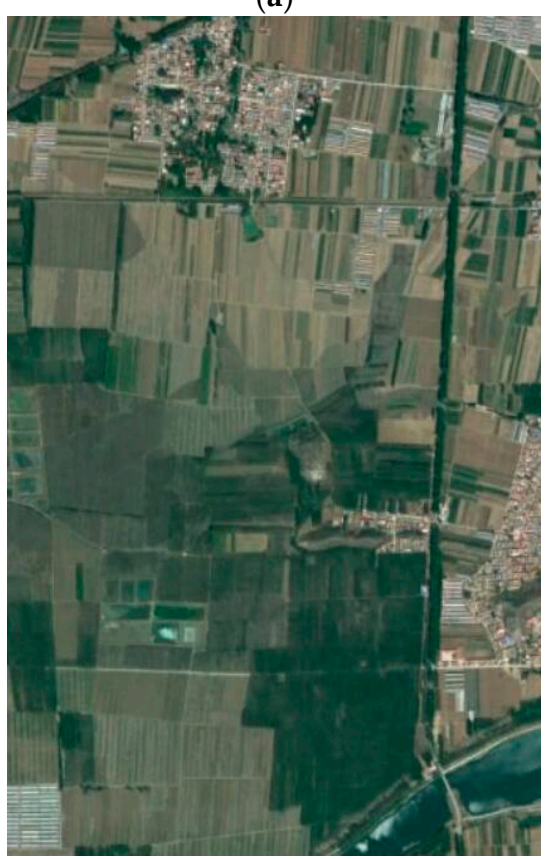

(c)

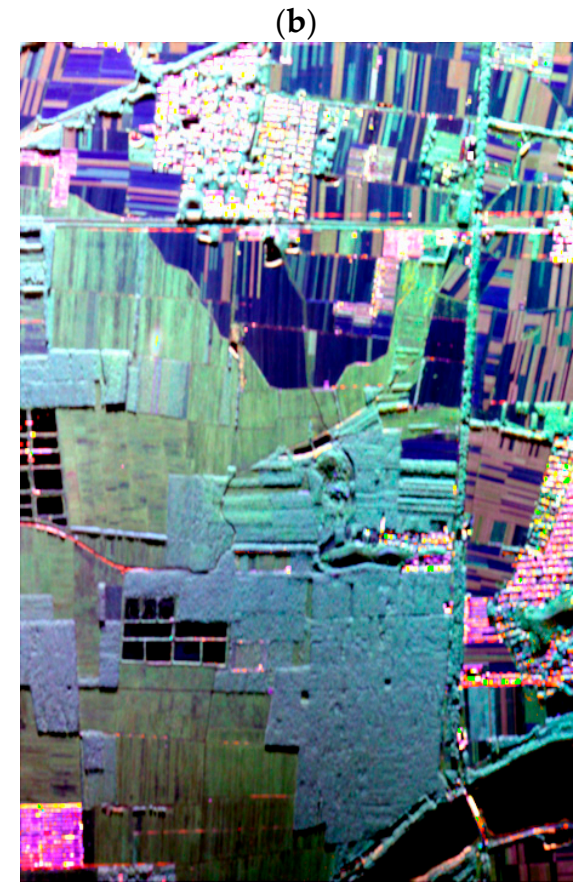

(d)

Figure 1. Test site location and images: (a) China; (b) district level map; (c) Google earth image; and (d) Pauli RGB image (Red: | HH - VVI, Green: | HVI, Blue: | HH + VV I). 


\subsection{Remote Sensing Data}

The C-band PolInSAR data were acquired on 26 September 2013 by the Multidimensional Space Joint-observation SAR (MSJosSAR) system in a quad polarization (HH, HV, VH, VV) repeat-pass interferometric mode, with a space baseline of $9 \mathrm{~m}$ and a time baseline of $30 \mathrm{~min}$. The original images were provided in a single-look complex (SLC) format with a pixel size of $0.5 \mathrm{~m} \times 0.5 \mathrm{~m}$ in azimuth and range directions, respectively. The polarization color composite image is shown in Figure 1d. The color scheme is based on the Pauli vector by assigning $|\mathrm{HH}-\mathrm{VVI},| \mathrm{HVI}$, and $|\mathrm{HH}+\mathrm{VV}|$ as red, green, and blue, respectively. In the Pauli basis, $|\mathrm{HH}-\mathrm{VVI},| \mathrm{HVI}$, and $|\mathrm{HH}+\mathrm{VV}|$ represent double bounce, volume, and single bounce scattering, respectively. Figure $1 \mathrm{~d}$ reveals that forested areas can be easily separated from open areas, but forest growth stages are almost indistinguishable.

\subsection{Ground Truth Data}

We did not collect field data in time synchronously with SAR data acquisition on 26 September 2013. We carried out field work on 3 October 2014 at the same temporal profile as the SAR data acquisition. Each land use/cover type is homogeneous and distributed evenly in this study area. In order to reduce the survey workload, only several locations of each type were selected to record GPS coordinates, take pictures, and describe other information of types, such as forest height, canopy coverage, and ground cover. Finally, a total of 30 samples were collected along the yellow lines (Figure 2): 4 for afforested land, 4 for young forest land, 4 for medium forest land, 4 for near-mature forest land, 3 for other stumpages, 3 for building land, 3 for wheat tillage land, 3 for corn stubble land, and 2 for water.

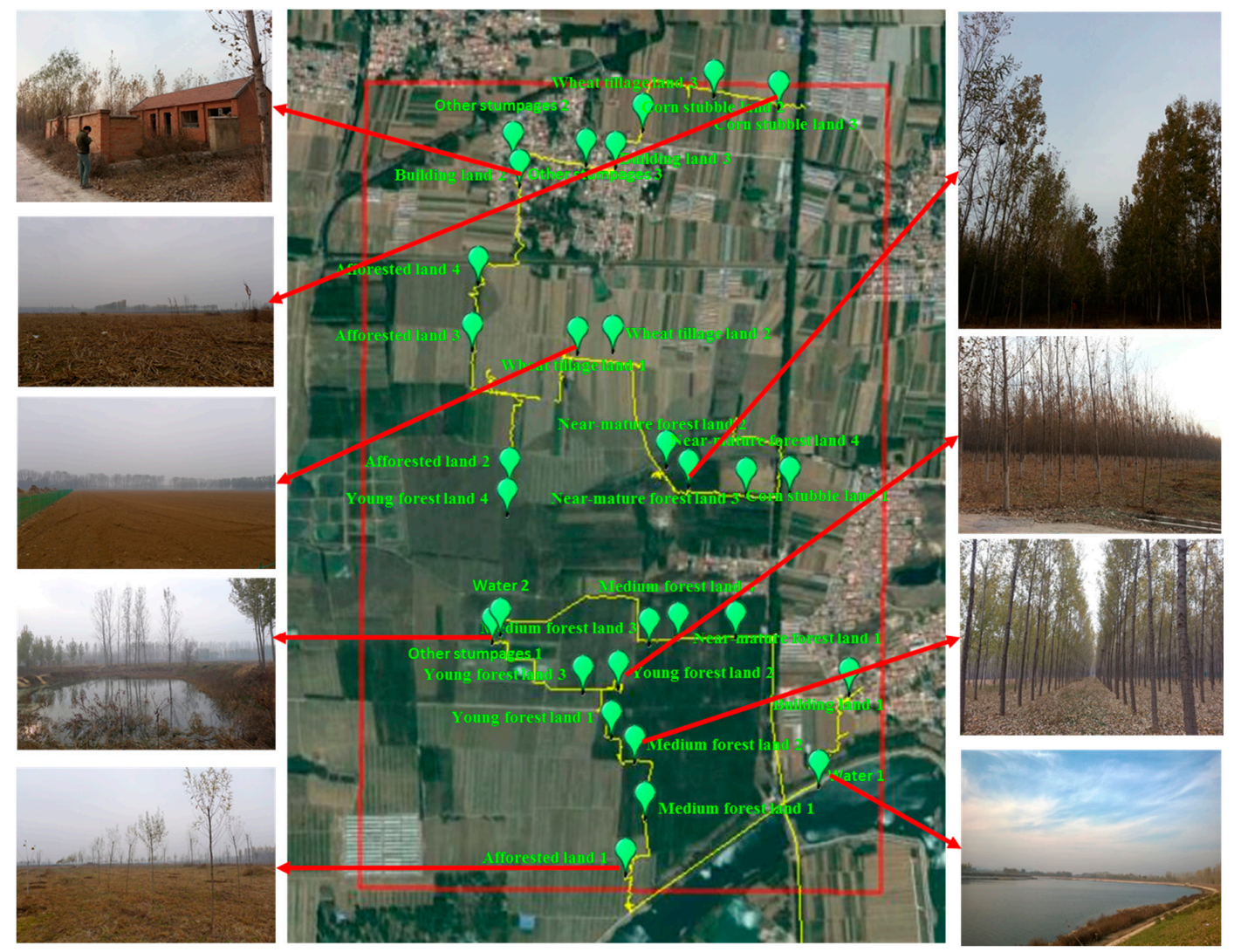

Figure 2. The location of ground truth samples and ground photos. Yellow lines represent the routes, while green points are the true ground locations of the samples. 
Sample coordinates were recorded by Differential Global Positioning System (DGPS, Trimble GEO XH6000) and the positional accuracy of GPS measurements for 30 samples were between 0.86 and $1.79 \mathrm{~m}$ after a differential calculation. It is worth noting that the positional accuracy of GPS measurements has no effect on training and validation samples, as the type is consistent within the positional error range.

The "National Technical Regulations for Inventory for Forest Management Planning and Design" issued by the State Forestry Administration was used in this study as the reference for the classification system of the test site. Additionally, field work provides the true conditions of the land use/cover, which was classified as 4 level-II types, including building land, water, farmland, and forest land. Specifically, farmland and forest land were divided into various subcategories, while components of each class are listed as follows.

The test site for farmland has a typical farming system of spring corn and winter wheat. The SAR data were acquired on 26 September 2013 and the field work was conducted on 3 October 2014. Spring corn is sown in late April and harvested in late August, so the spring corn was already harvested at this time, with remaining stubble. This did not change between the data acquisition and field work time. Winter wheat is seeded in early October and harvested in the following June, so it had been turned over at data acquisition time. Therefore, there may be individual wheat plots that were seeded during the field work, while the land surface characteristics can be treated as no changes to data acquisition time. Therefore, farmland was divided into two subcategories: corn stubble and wheat tillage land.

For the forest land, Populus is almost the only tree species in the test site. Thus, it is not appropriate to classify forest by different tree species. We confirmed the forest planting time from local forestry department. Due to the difference in tree seedlings and planting times, forest growth stage types were defined based on age group as afforested land (younger than 2 years), young forest land (2 to 5 years), medium forest land (6 to 10 years), and near-mature forest land (11 to 15 years). This was done according to the "National Technical Regulations for Inventory for Forest Management Planning and Design".

Additionally, the trees distributed around villages, ponds, and afforested land were defined as other stumpages in this study, such as scattered trees.

Overall, the classification system of the test sites contains nine classes (Table 1), including four forest land types (afforested land, young forest land, medium forest land and near-mature forest land) and five non-forested types (other stumpages, water, building land, corn stubble land, and wheat tillage farmland).

Table 1. Descriptions of land use/cover types.

\begin{tabular}{cl}
\hline \multicolumn{1}{c}{ Type } & \multicolumn{1}{c}{ Description } \\
\hline Afforested land & $\begin{array}{l}\text { Tree height is about } 2 \mathrm{~m} \text { and canopy is open. Ground surface is covered } \\
\text { with withered grass. }\end{array}$ \\
\hline Young forest land & $\begin{array}{l}\text { Tree height is about } 4 \mathrm{~m} \text { and canopy is relatively open. Ground surface } \\
\text { is covered with litter falls or shrub. }\end{array}$ \\
\hline Medium forest land & $\begin{array}{l}\text { Tree height is about } 7 \mathrm{~m} \text { and canopy is relatively closed. Ground surface } \\
\text { is covered with litter falls. }\end{array}$ \\
\hline Near-mature forest land & $\begin{array}{l}\text { Tree height is about } 9 \mathrm{~m} \text { and canopy is closed. Ground surface is } \\
\text { covered with litter falls. }\end{array}$ \\
\hline Other stumpages & $\begin{array}{l}\text { Scattered trees, four-side trees, a few characteristics of them are similar } \\
\text { to those of near-mature forest. }\end{array}$ \\
\hline Water & Open surface water bodies such as rivers and lakes. \\
\hline Building land & Some are mixed with trees. \\
\hline Wheat tillage land & Wheat has been harvested and surface soil has been turned over. \\
\hline Corn stubble land & Corn has been harvested and surface is covered with straw. \\
\hline
\end{tabular}




\section{Methods}

\subsection{PolSAR Data Processing}

\subsubsection{Polarimetric Information Extraction}

The PolSAR image (the master image of the PolInSAR dataset) was pre-processed using the PolSARpro5.0 software. The PolSAR image was first multi-looked with three looks in azimuth and three looks in range to generate the Hermitian positive semi-definite covariance (C3) matrix. This was then filtered with a $5 \times 5$ mean filter to minimize speckle noise.

Polarimetric decompositions were then applied to extract the meaningful decomposition parameters of each land use/cover type. The Freeman-Durden and Cloude-Pottier decomposition method, the two most frequently applied methods, were adopted in this study. The Freeman-Durden decomposition was carried out to distinguish the backscattering for each image pixel into the three scattering mechanisms: rough-surface scattering, double-bounce scattering, and volume scattering.

The Cloude-Pottier decomposition was used to extract the entropy $(H)$, anisotropy $(A)$, and alpha angle $(\alpha)$ parameters of each image pixel. $H$ indicates the amount of mixing between scattering mechanisms, where a value close to 0 indicates a single scattering mechanism and values close to 1 indicate equal scattering mixtures. $A$ indicates the amount of mixing between the second and third scattering mechanisms, where a value close to 0 represents equal proportions and a value close to 1 represents domination of the second mechanism. $\alpha$ ranges from 0 to $90^{\circ}$, with surface scattering associated with low values $\left(<40^{\circ}\right)$, double bounce associated with intermediate values $\left(40^{\circ}\right.$ to $\left.52.5^{\circ}\right)$, and volume scattering associated with high values $\left(>52.5^{\circ}\right)[36]$.

\subsubsection{RK Texture Information Extraction}

We modeled the vector of polarimetric scattering coefficients using product models of a non-Gaussian texture term and a multivariate Gaussian-based speckle term. The relative kurtosis $(R K)$ is the sample multivariate kurtosis relative to that of the standard multivariate Gaussian and is a common measure of non-Gaussianity for the generalized Wishart distribution [37]:

$$
R K=\frac{\text { mean }\left[\left(y^{T} \hat{\Sigma}^{-1} y\right)^{2}\right]}{d(d+1)}=\frac{E\left\{z^{2}\right\}}{(E\{z\})^{2}}
$$

where $y$ is the vector of polarimetric scattering coefficients, and $z$ is a strictly positive random variable. After derivation, we can get

$$
R K=\frac{L \cdot \operatorname{var}\left\{\operatorname{tr}\left(\hat{\Sigma}^{-1} C\right)\right\}+d^{2}}{d(d+1)}
$$

where $L$ is the number of looks, $d$ is the vector dimension, and $\Sigma$ is the mean covariance matrix.

\subsubsection{Coherence Information Extraction}

The PolInSAR dataset of this test site was used to form the $6 \times 6$ interferometric coherency matrix as shown in Equation (3):

$$
T=\left[\begin{array}{l}
k_{1} \\
k_{2}
\end{array}\right]\left[\begin{array}{ll}
k_{1}^{* T} & k_{2}^{* T}
\end{array}\right]=\left[\begin{array}{cc}
T_{11} & \Omega_{12} \\
\Omega_{12}^{* T} & T_{22}
\end{array}\right]
$$


with

$$
k_{i}=\frac{1}{\sqrt{2}}\left[\begin{array}{c}
S_{H H}+S_{V V} \\
S_{H H}-S_{V V} \\
2 S_{H V}
\end{array}\right]
$$

where Subscripts 1 and 2 denote the measurement of the two ends of the spatial baseline, respectively. Following this, the polarimetric interferometric coherence can be derived as a function of the polarization of the two images corresponding to the two ends of the spatial baseline:

$$
\gamma\left(\omega_{1}, \omega_{2}\right)=\frac{\omega_{1}^{* T} \Omega_{12} \omega_{2}}{\sqrt{\left(\omega_{1}^{* T} T_{11} \omega_{1}\right)\left(\omega_{2}^{* T} T_{22} \omega_{2}\right)}}
$$

where $\omega_{1}$ and $\omega_{2}$ are the unitary complex vectors, which define the polarization of the two images. Based on a polarimetric interferometric coherence optimization method, an optimal coherence set can be defined as follows [38]:

$$
\left(\widetilde{\gamma}_{o p t 1}, \widetilde{\gamma}_{o p t 2}, \widetilde{\gamma}_{o p t 3}\right) \text { with }\left|\widetilde{\gamma}_{o p t 1}\right| \geq\left|\widetilde{\gamma}_{o p t 2}\right| \geq\left|\widetilde{\gamma}_{o p t 3}\right| .
$$

From this, the two optimal coherence parameters $\left(A_{1}\right.$ and $\left.A_{2}\right)$ indicate relative amplitude variations between the different optimized channels, which are defined in [26] as follows:

$$
A_{1}=\frac{\widetilde{\gamma}_{o p t \_1}-\widetilde{\gamma}_{o p t \_2}}{\widetilde{\gamma}_{o p t \_1}}, A_{2}=\frac{\widetilde{\gamma}_{o p t \_1}-\widetilde{\gamma}_{o p t \_3}}{\widetilde{\gamma}_{o p t \_1}}
$$

with

$$
\widetilde{\gamma}_{\text {opt } \_i}=\frac{\left|\widetilde{\gamma}_{\text {opti }}\right|}{\sum_{j=1}^{3}\left|\widetilde{\gamma}_{\text {optj }}\right|} i=1,2,3 .
$$

As shown in Table 2, a total of 13 features were derived from the above methods. The scheme involves an independent analysis of the capabilities of polarimetric, texture, and coherence features for

\begin{tabular}{|c|c|c|c|c|}
\hline ID & Classificatic & Features & Descriptions & References \\
\hline 1 & Polarization features & $\begin{array}{l}P_{\mathrm{s}}, P_{\mathrm{d}}, P_{\mathrm{v}} \\
H, A, \alpha\end{array}$ & $\begin{array}{l}\text { Freeman-Durden Decomposition parameters } \\
\text { Cloud-Pottier Decomposition parameters }\end{array}$ & $\begin{array}{l}{[19]} \\
{[20]}\end{array}$ \\
\hline 2 & Texture features & $R K$ & Relative Kurtosis texture & [36] \\
\hline 3 & Coherence features & $\begin{array}{c}\gamma_{\mathrm{HH}}, \gamma_{\mathrm{HV}}, \gamma_{\mathrm{VV}} \\
\gamma_{o p t_{-} 1}, \gamma_{o p t \_2}, \gamma_{o p t \_3} \\
A_{1}, A_{2}\end{array}$ & $\begin{array}{c}\text { Polarimetric interferometric coherence } \\
\text { Optimal coherence } \\
\text { Optimal coherent spectrum }\end{array}$ & [26] \\
\hline
\end{tabular}
the separability of land use/cover types for the selection of the relative optimal features. Following this, the polarimetric features were used for land use/cover types using SVM, followed by a combination of texture and coherence features.

Table 2. Classification feature descriptions.

\subsection{SVM Classification Method}

As a supervised non-parametric statistical learning technique, the support vector machine (SVM) classifier has been mostly applied in land use/cover classification based on hyperspectral remotely sensed data, with only a few based on SAR data [39-41]. SVM is well suited to handle linearly non-separable cases by using a hyperplane. The hyperplane can be found easily using Kernel theory to transform the features from low dimensional space to high dimensional space [42]. The Kernal theory is one of the core concepts in SVMs and plays a very important role. A Gaussian radial basis function kernel algorithm for the SVM was chosen because it has the ability to handle more complex non-linear class distributions [34,35]. 
The Gaussian Kernel theory is as follows:

$$
k\left(X_{i}, Y_{i}\right)=\exp \left(\frac{-\left\|X_{i}-Y_{i}\right\|^{2}}{2 \sigma^{2}}\right)
$$

where $k\left(X_{i}, Y_{i}\right)$ defines the kernel, $X_{i}$ and $Y_{i}$ are the data being separated, and the spread width $\sigma$ of Gaussian kernel includes adjustable kernel function parameters.

In the field work, we collected several samples of each type. Due to non-forest types conforming to SAR scattering properties, such as water, building land, wheat tillage land, and corn stubble land, non-forest types distribution can be confirmed on the Pauli RGB image. These additional samples of the non-forest type were collected as Pauli RGB images according to ground true data. While forest growth stage types have no obvious differences in the Pauli RGB image, each distribution of the forest growth stage type and more samples were confirmed and collected based on a similar spectrum and spatial characteristics from high spatial resolution images of Google Earth according to ground true data. Finally, 340 samples were collected, each of which was an area of interest (AOI), as shown in Figure 3. Most of the land use/cover types have 40 AOIs (Table 3), except 20 AOIs for water. Two-thirds of the AOIs for each land use/cover type were used as training AOIs, and the rest were test AOIs. Table 3 also shows the total number of pixels corresponding to the total number of AOIs for each land use/cover type.
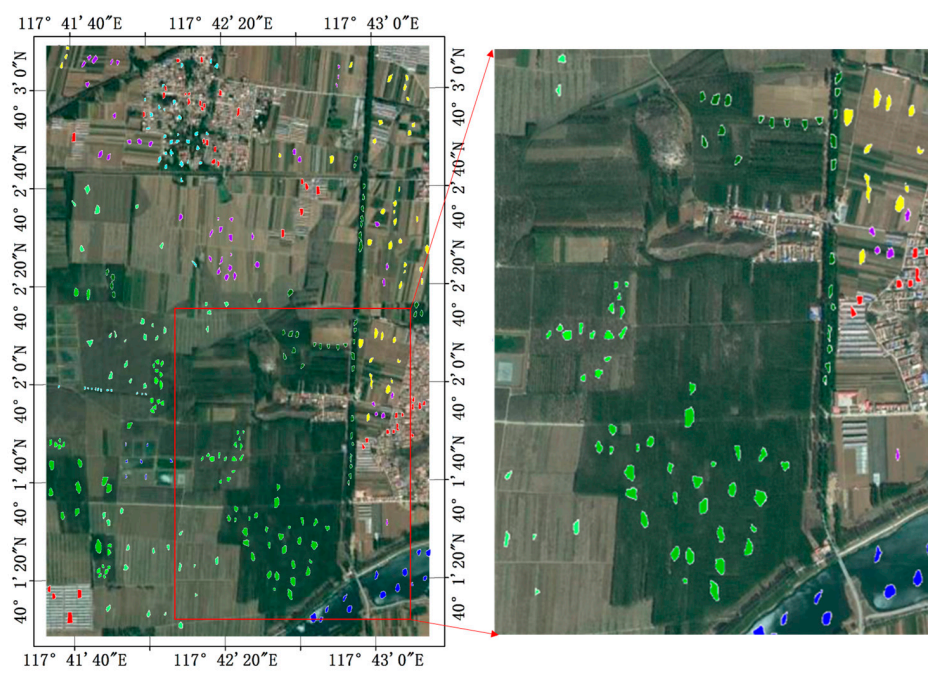

(a)
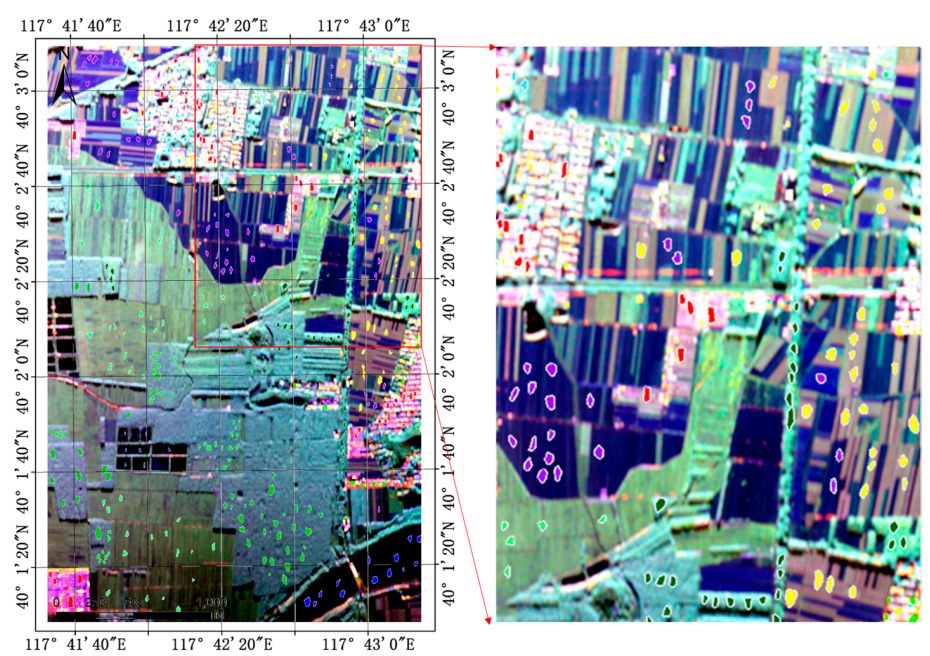

(b)

Figure 3. Distribution of samples: (a) Google Earth image; (b) Pauli RGB image. 
Table 3. Numbers of AOIs and pixels for each land use/cover type.

\begin{tabular}{ccc}
\hline Type & Number of AOIs & Number of Pixels \\
\hline Afforested land & 40 & 6034 \\
Young forest land & 40 & 4353 \\
Medium forest land & 40 & 11,146 \\
Near-mature forest land & 40 & 4640 \\
Other stumpages & 40 & 2421 \\
Water & 20 & 4235 \\
Building land & 40 & 5699 \\
Wheat tillage land & 40 & 5465 \\
Corn stubble land & 40 & 6465 \\
\hline
\end{tabular}

\section{Results}

\subsection{Capabilities of Classification Features}

To evaluate the ability of various features to distinguish land use/cover types, histograms of polarization, texture, and coherence features were generated to analyze the separability of land use/cover types.

\subsubsection{Polarization Feature}

In Figure $4 \mathrm{a}, \mathrm{b}$, the RGB images are composited by Freeman-Durden decomposition parameters $\left(P_{\mathrm{d}}, P_{\mathrm{v}}, P_{\mathrm{s}}\right.$ and Table 2$)$ and Cloude-Pottier decomposition parameters $(\alpha, H, A$ and Table 2$)$, respectively. The non-forest lands (water, farmland, building land, and afforested land) were recognized visually from the two images. However, only Cloude-Pottier decomposition highlighted the variations between different forest types.

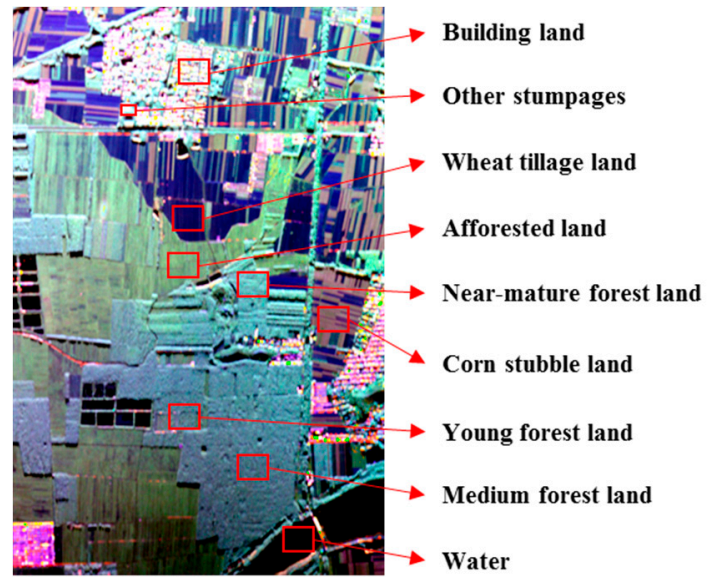

(a)

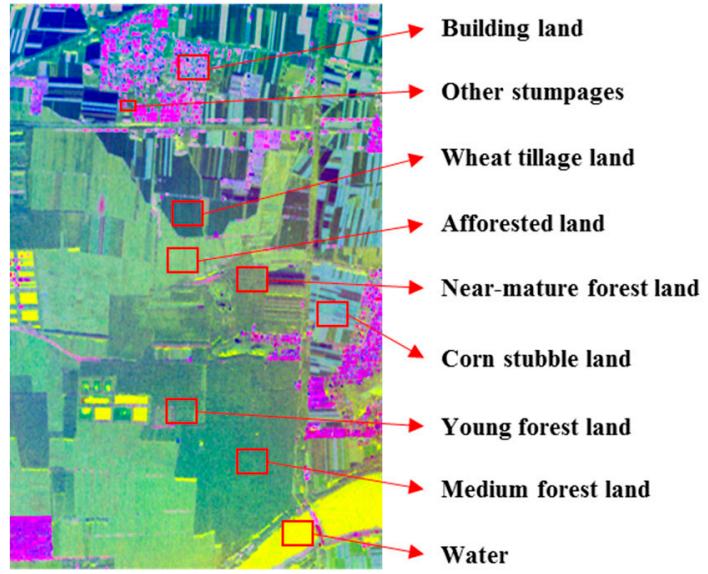

(b)

Figure 4. RGB images composited by polarimetric features: (a) Freeman-Durden decomposition (Red: $P_{\mathrm{d}}$, Green: $P_{\mathrm{v}}$, and Blue: $P_{\mathrm{s}}$ ); (b) Cloud-Pottier decomposition (Red: $\alpha$, Green: $H$, and Blue: $A$ ).

Histograms in Figure 5 represent the separability of different types using different features. For forestland types, the histograms are confusion due to their similar vegetation structural characteristics (Figure $5 \mathrm{a}-\mathrm{c}$ ). Therefore, it is challenging to distinguish various forest growth types using the features obtained from Freeman-Durden decomposition. The $H$ obtained from Cloude-Pottier decomposition can be used to separate afforested land from other forest land types in general (Figure 5d). It is possible for the $\alpha$ to be used to differentiate between medium forest land and near-mature forest land/afforested land (Figure 5e). However, histograms of the afforested land and near-mature forest land overlap, while the young forest land is mixed with the medium forest land 
and near-mature forest land. Using the polarimetric features, the young forest land, medium forest land, and near-mature forest land are difficult to separate.

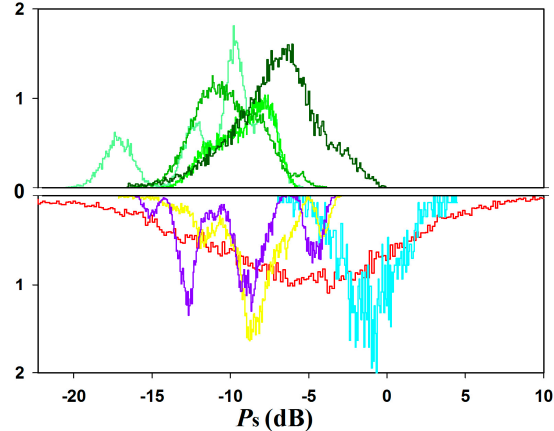

(a)

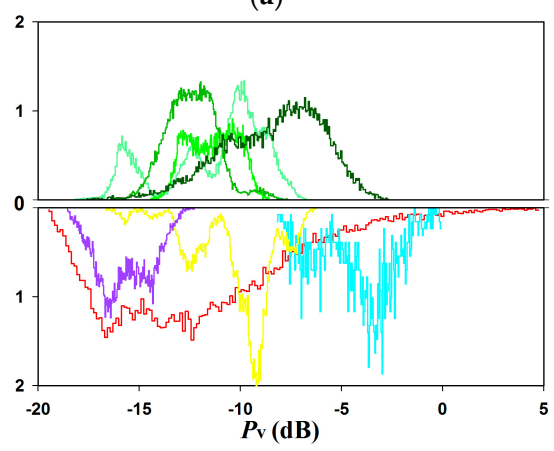

(c)

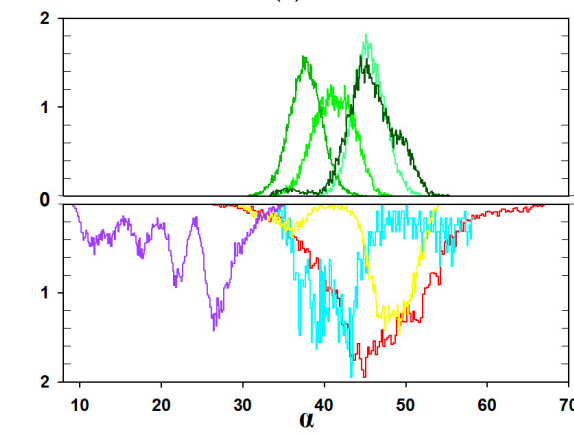

(e)

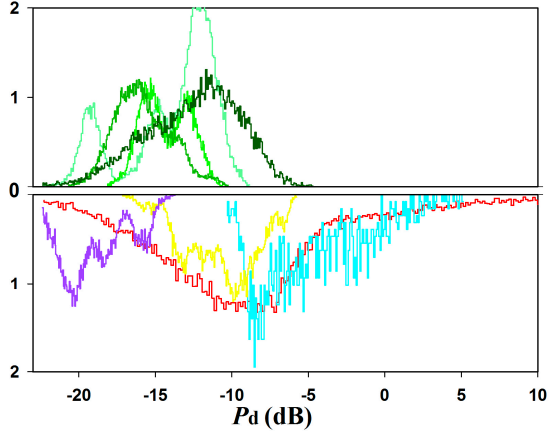

(b)

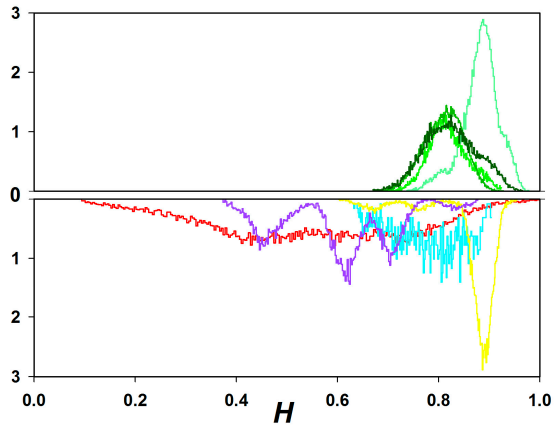

(d)

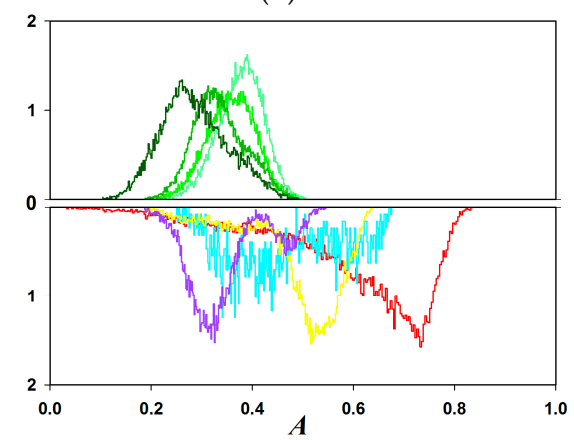

(f)

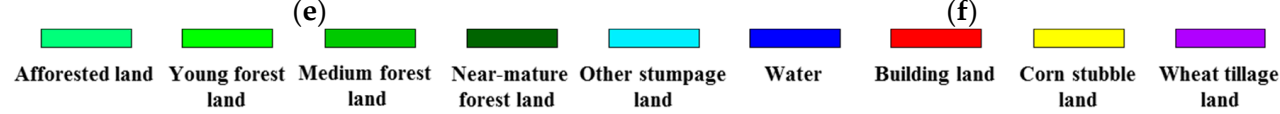

Figure 5. Histograms of polarimetric decomposition features: (a) $P_{\mathrm{s}}$; (b) $P_{\mathrm{d}} ;$ (c) $P_{\mathrm{v}}$; (d) $H$; (e) $\alpha$; (f) $A$.

For non-forest types, $P_{\mathrm{s}}$ obtained from Freeman-Durden decomposition can be used to separate other stumpages from wheat tillage farmland and corn stubble land, although the latter two are usually confused. Histograms of $P_{\mathrm{d}}, H, \alpha$, and $A$ show a high separability between wheat tillage farmland and corn stubble land, while other stumpages are difficult to differentiate. $P_{\mathrm{v}}$ performs well for the separation of wheat tillage farmland, corn stubble land, and other stumpages. Building land is confused with other types.

Additionally, as shown in Figure $5, A, P_{\mathrm{d}}$, and $H$ can be used to separate forest types from wheat tillage farmland, stumpages, and corn stubble land, respectively.

Overall, all of the polarimetric features, with their particular advantages, can be used for classification. These features are effective for separation among non-forest types as well as distinguishing medium forest land and near-mature forest land; however, it is difficult to identify other forested types by using these polarimetric features. 


\subsubsection{Texture}

Figure 6 shows the $R K$ texture image calculated by the non-Gaussian statistical modeling theory (Table 2) and visually highlights the building land. However, there is no obvious difference between medium forest land and young forest land/near-mature forest land.

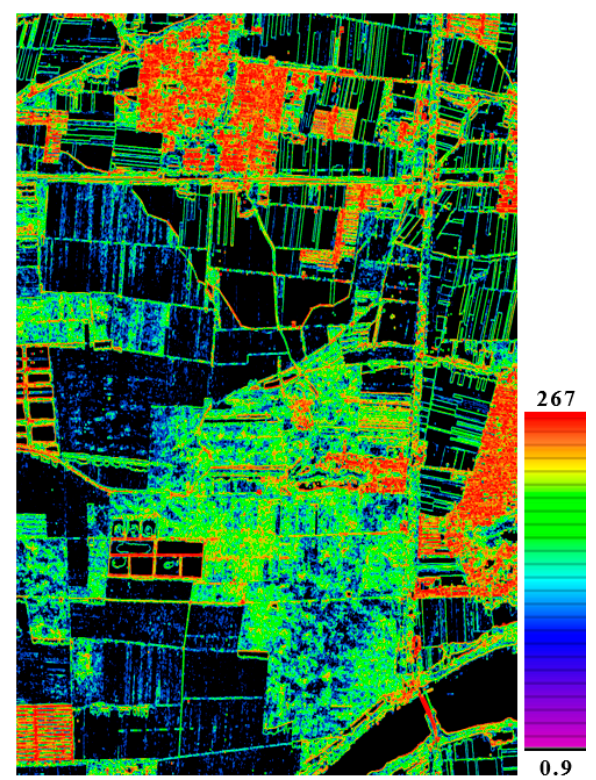

Figure 6. Relative kurtosis $(R K)$ texture image.

Figure 7 demonstrates the separability of different types by the $R K$ feature histogram. Among the three levels of $R K$ values (Figure 7), the building land expresses the highest $R K$ value due to its significant spatial heterogeneity, followed by near-mature forest land, stumpage, medium forest land and young forest land. Farmland and afforested land show the lowest $R K$ values.

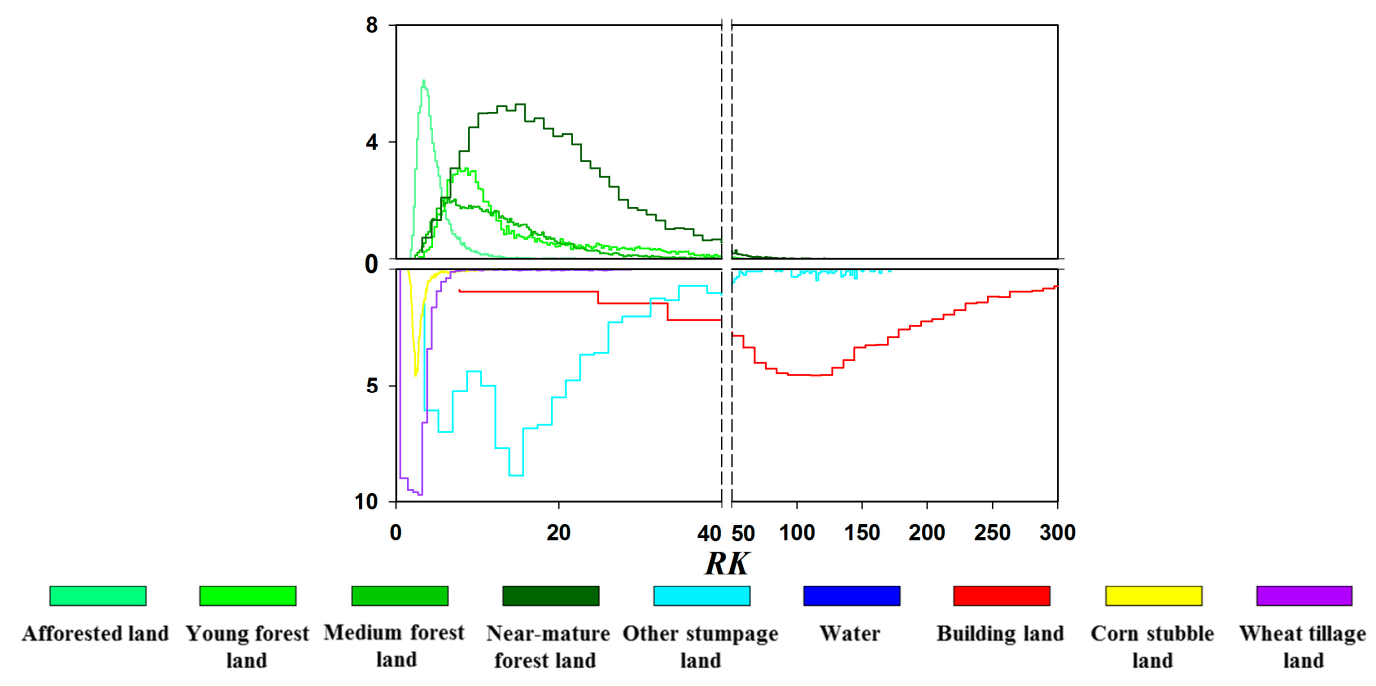

Figure 7. Histogram of $R K$ texture.

Afforested land and farmland is mainly characterized by bare soil. Therefore, both types can be confused with each other in terms of spatial heterogeneity. Forest plantations have the regular structure, which leads to a similar spatial heterogeneity for young forest land, medium forest land, and near-mature forest land. Hence, their histograms tend to overlap. However, texture features play 
a main role in separating afforested land from other forest types, in addition to separating building land from other types [43].

\subsubsection{Coherence Features}

Figure 8 represents the coherence features obtained from PolInSAR data, including polarimetric interferometric coherence features $\left(\gamma_{\mathrm{HH}}, \gamma_{\mathrm{HV}}, \gamma_{\mathrm{VV}}\right.$, Table 2, Figure 8a), optimal coherence features $\left(\gamma_{o p t} 1, \gamma_{o p t} 2, \gamma_{o p t \_3}\right.$, Table 2, Figure $\left.8 \mathrm{~b}\right)$ and optimal coherent spectrum features $\left(A_{1}, A_{2}\right.$, Table 2, Figure $8 \mathrm{c}, \mathrm{d})$. Compared to Figures 4 and 6, Figure 8 obviously highlights the differences between medium forest land and young forest land, although it cannot distinguish medium forest land and near-mature forest land.

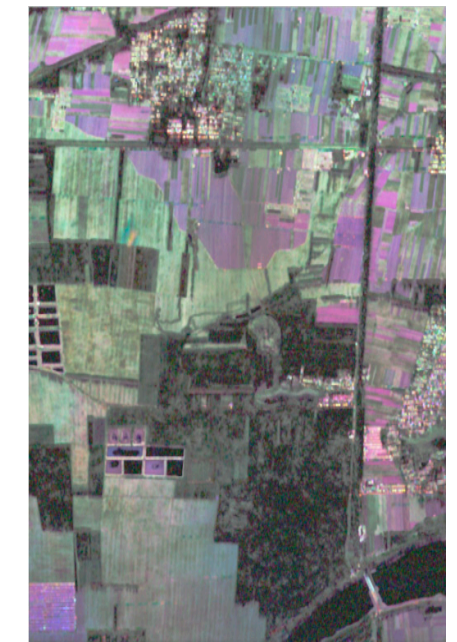

(a)

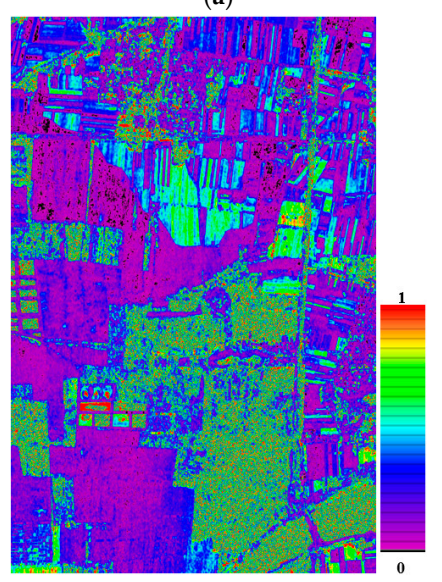

(c)

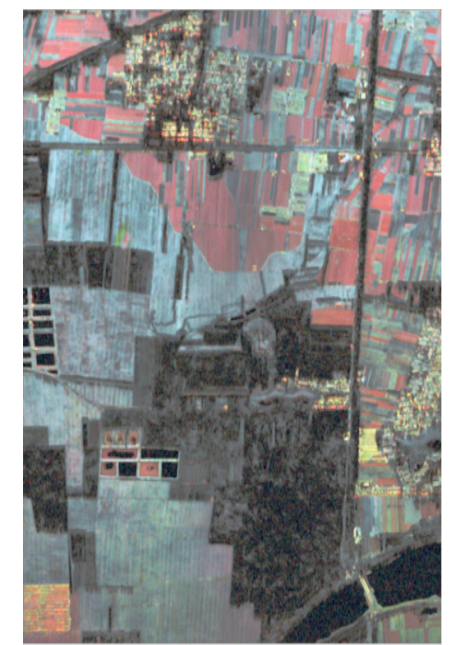

(b)

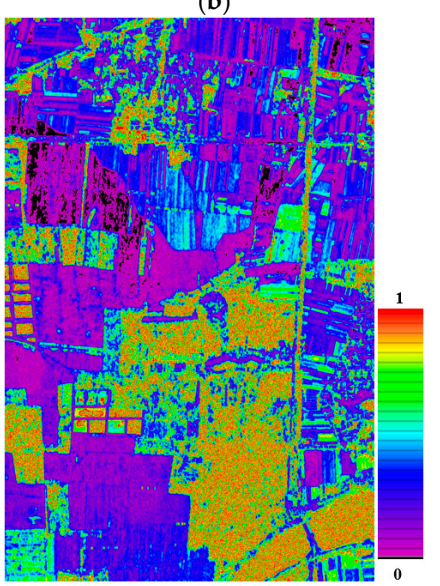

(d)

Figure 8. RGB images composited by coherence features: (a) polarimetric interferometric coherence (Red: $\gamma_{\mathrm{HH}}$, Green: $\gamma_{\mathrm{HV}}$, and Blue: $\left.\gamma_{\mathrm{VV}}\right) ;(\mathbf{b})$ optimal coherence (Red: $\gamma_{\text {opt_1 }}$, Green: $\gamma_{\text {opt_2}}$, and Blue: $\left.\gamma_{\text {opt_3}}\right)$; (c) optimal coherent spectrum $\left(A_{1}\right)$; (d) optimal coherent spectrum $\left(A_{2}\right)$.

Figure 9 displays the corresponding histogram performances for the eight coherence features. Compared to the polarimetric interferometric coherence (Figure 9a-c), the coherences of all types are improved by the polarimetric interferometric coherence optimization method (Figure 9d,e). Obviously, the coherence of afforested land is the highest, followed by young forest land and near-mature forest land, which is consistent with previous studies, as coherence is inversely proportional to the structural complexity of a forest [44-46]. For non-forest types, the coherence of buildings, wheat, and corn are higher than stumpage. The variance of the former is smaller in $\gamma_{o p t}{ }_{1}$, while the latter is smaller in $\gamma_{\text {opt_2}}$. 


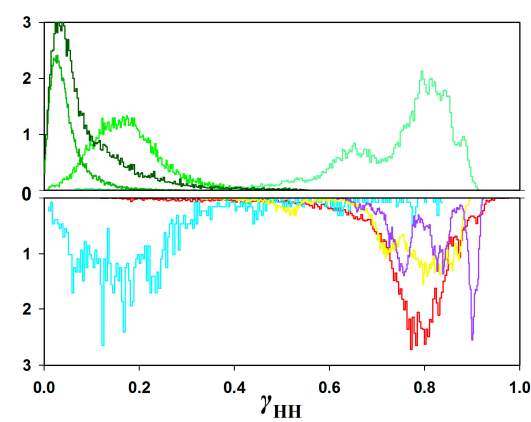

(a)

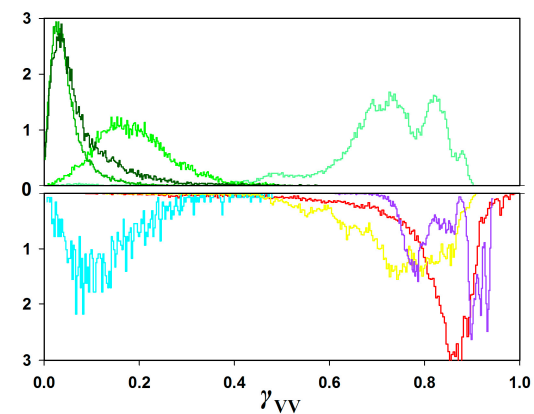

(c)

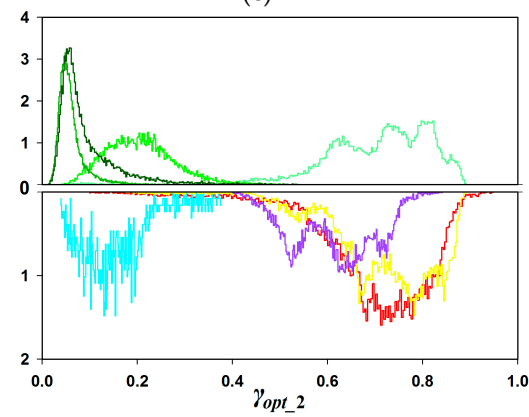

(e)

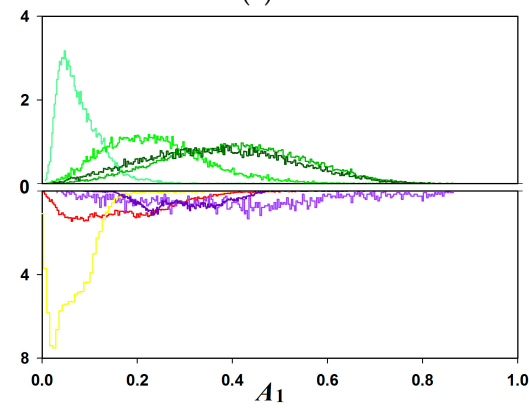

(g)

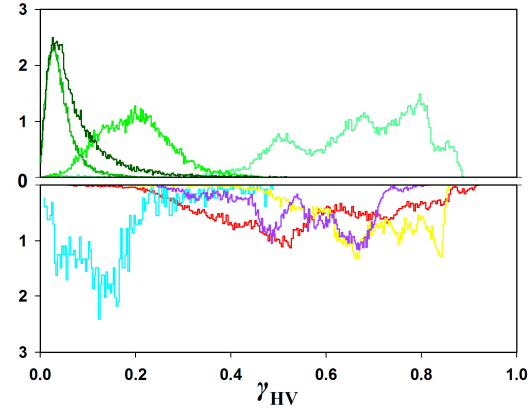

(b)

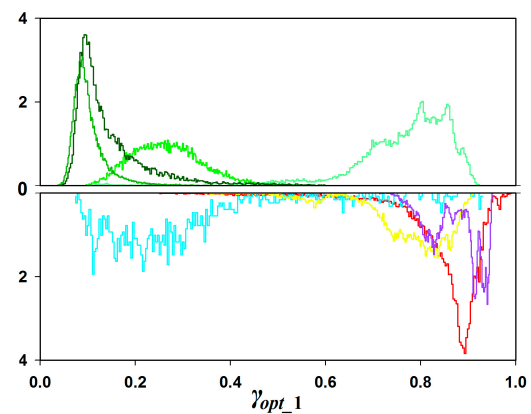

(d)

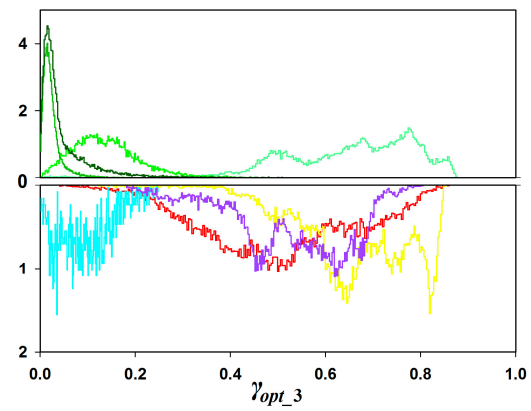

(f)

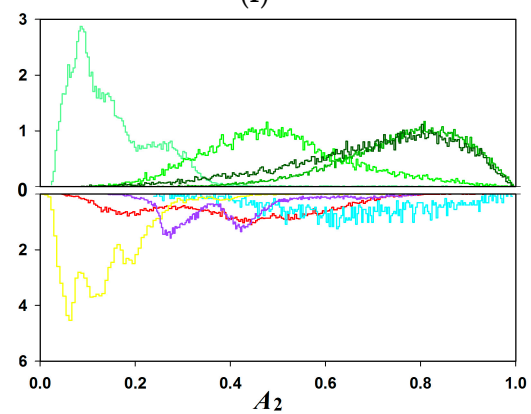

(h)

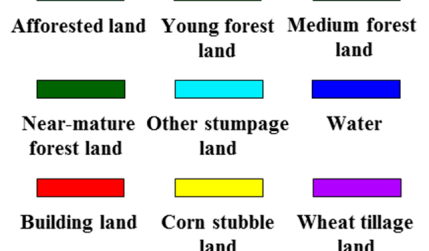

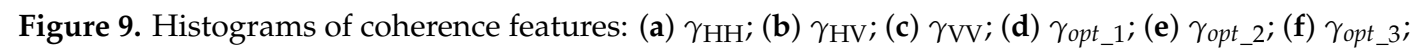
(g) $A_{1} ;(\mathbf{h}) A_{2}$.

$A_{1}$ and $A_{2}$ indicate the relative amplitude variations between the different optimized channels. A value of $A_{1}$ close to 1 indicates a single coherent scattering mechanism in the resolution cell, which is 
related to a complex structure or dense forest with high level biomass and low coherence. Values of $A_{1}$ and $A_{2}$ that are both close to zero depict a low dependence of the scattering coherence on the polarization information, which is related to a simple structure or sparse forest with low level biomass and high coherence. We found that $A_{2}$ is more sensitive to the forest structure than $A_{1}$ (Figure 9g,h).

Following this, three coherence features $\left(\gamma_{o p t \_}, \gamma_{o p t} 2\right.$ and $\left.A_{2}\right)$ are selected for classification in this study, especially for distinguishing young forest land and medium forest land. The only drawback is that neither optimal coherence nor optimal coherent spectrum can distinguish medium forest land and near-mature forest land effectively. However, this can be improved by using combined polarimetric features.

\subsection{Classification Results}

To analyze the effects of the three group features (polarimetric, texture, and coherence features) on classification behavior, the first experiment was conducted using only the polarimetric features (Figure 10a). The second experiment was conducted using polarimetric and texture features (Figure 10b). Finally, in the third experiment, polarimetric, texture, and coherence features were all used for the classification (Figure 10c). Although misclassifications are inevitable, the results in Figure 10a suggest that non-forest types can be distinguished in general. Adding the texture features to the polarimetric features, the classifications for buildings and afforested land were slightly improved, as shown in Figure 10b. Moreover, the separation between young forest land and medium forest land is largely improved by taking advantage of the coherence (Figure 10c). However, there are still misclassifications between near-mature forest land and other stumpages.

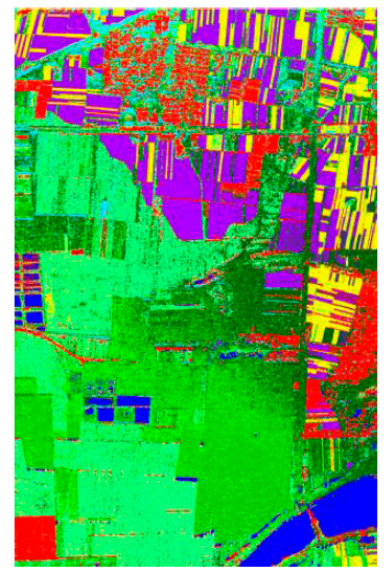

(a) Pol

Afforested land Young forest Medium forest land

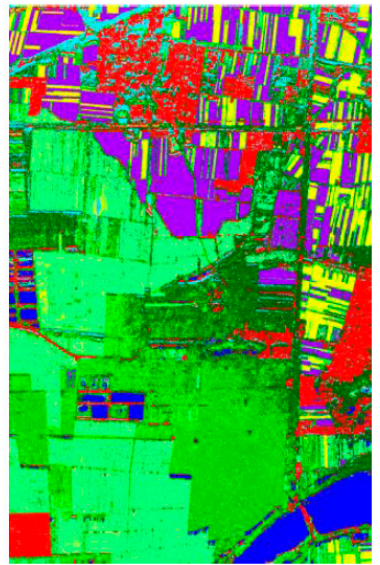

(b) Pol + RK

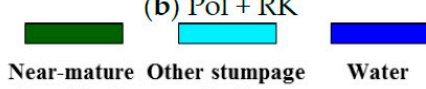

forest land land

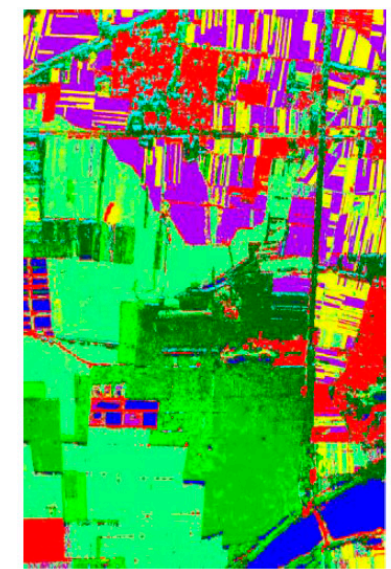

(c) $\mathrm{Pol}+\mathrm{RK}+\mathrm{Coh}$

Building land Corn stubble Wheat tillage land land

Figure 10. (a) Classification results from polarimetric features; (b) classification results from texture features; (c) classification results from coherence features.

The classification accuracy of three experiments were evaluated by the pixels of test AOIs based on the confusion matrix (Tables 4-6), which contains the producer's accuracy (PA, as shown in (9)), user's accuracy (UA, as shown in (10)), overall accuracy (OA, as shown in (11)), and Kappa coefficient (Kap, as shown in (12)). For each line of the confusion matrix, each datum represents the pixel number of omission. For each column, each data means the pixel number of misclassification. For the third experiment, OA was $90.9 \%$, which increased by $8 \%$ and $5 \%$ compared to the first experiment and second experiment, respectively. Specifically, the PA of afforested land, young forest land, medium forest land, and near-mature forest land improved by $6 \%, 31 \%, 11 \%$, and $6 \%$, respectively. This accuracy evaluation also demonstrates that coherence features are an important indicator in the classification of forest types. 
Table 4. The confusion matrix of classification results from polarimetric features.

\begin{tabular}{|c|c|c|c|c|c|c|c|c|c|c|c|}
\hline & & \multicolumn{9}{|c|}{ Classification Image } & \multirow[b]{2}{*}{ PA $(\%)$} \\
\hline & & $\begin{array}{l}\text { Afforested } \\
\text { Land }\end{array}$ & $\begin{array}{l}\text { Young } \\
\text { Forest } \\
\text { Land }\end{array}$ & $\begin{array}{l}\text { Medium } \\
\text { Forest } \\
\text { Land }\end{array}$ & $\begin{array}{l}\text { Near-Mature } \\
\text { Forest } \\
\text { Land }\end{array}$ & $\begin{array}{c}\text { Other } \\
\text { Stumpages }\end{array}$ & Water & $\begin{array}{l}\text { Building } \\
\text { Land }\end{array}$ & $\begin{array}{l}\text { Wheat } \\
\text { Tillage } \\
\text { Land }\end{array}$ & $\begin{array}{l}\text { Corn } \\
\text { Stubble } \\
\text { Land }\end{array}$ & \\
\hline \multirow{10}{*}{$\begin{array}{c}\text { Reference } \\
\text { data }\end{array}$} & Afforested land & 2697 & 110 & 37 & 153 & 12 & 0 & 25 & 36 & 0 & 87.9 \\
\hline & Young forest land & 84 & 479 & 221 & 122 & 0 & 0 & 3 & 0 & 0 & 52.7 \\
\hline & Medium forest land & 101 & 508 & 1878 & 37 & 0 & 0 & 4 & 4 & 4 & 74.1 \\
\hline & Near-mature forest land & 65 & 47 & 30 & 831 & 138 & 0 & 32 & 15 & 1 & 71.7 \\
\hline & Other stumpages & 0 & 1 & 0 & 4 & 70 & 1 & 1 & 0 & 0 & 91.0 \\
\hline & Water & 0 & 0 & 0 & 1 & 0 & 594 & 0 & 0 & 0 & 99.8 \\
\hline & Building land & 65 & 12 & 10 & 123 & 124 & 3 & 2202 & 37 & 13 & 85.1 \\
\hline & Wheat tillage land & 23 & 5 & 1 & 9 & 8 & 0 & 18 & 1044 & 1 & 94.1 \\
\hline & Corn stubble land & 3 & 1 & 18 & 39 & 0 & 0 & 3 & 0 & 1000 & 94.0 \\
\hline & UA (\%) & 88.8 & 41.2 & 85.6 & 63.0 & 19.8 & 99.3 & 96.2 & 91.9 & 98.1 & \\
\hline
\end{tabular}

Note: Overall accuracy (OA) is 82.4 ; Kappa coefficient (Kap) is 0.79 .

Table 5. The confusion matrix of classification results from polarimetric features combined with texture features.

\begin{tabular}{|c|c|c|c|c|c|c|c|c|c|c|c|}
\hline & & \multicolumn{9}{|c|}{ Classification Image } & \multirow[b]{2}{*}{ PA $(\%)$} \\
\hline & & $\begin{array}{l}\text { Afforested } \\
\text { Land }\end{array}$ & $\begin{array}{l}\text { Young } \\
\text { Forest } \\
\text { Land }\end{array}$ & $\begin{array}{l}\text { Medium } \\
\text { Forest } \\
\text { Land }\end{array}$ & $\begin{array}{l}\text { Near-Mature } \\
\text { Forest } \\
\text { Land }\end{array}$ & $\begin{array}{c}\text { Other } \\
\text { Stumpages }\end{array}$ & Water & $\begin{array}{l}\text { Building } \\
\text { Land }\end{array}$ & $\begin{array}{l}\text { Wheat } \\
\text { Tillage } \\
\text { Land }\end{array}$ & $\begin{array}{l}\text { Corn } \\
\text { Stubble } \\
\text { Land }\end{array}$ & \\
\hline \multirow{10}{*}{$\begin{array}{l}\text { Reference } \\
\text { data }\end{array}$} & Afforested land & 2864 & 75 & 39 & 32 & 1 & 0 & 2 & 56 & 1 & 93.3 \\
\hline & Young forest land & 52 & 569 & 177 & 109 & 0 & 0 & 2 & 0 & 0 & 62.6 \\
\hline & Medium forest land & 45 & 560 & 1885 & 41 & 0 & 0 & 2 & 3 & 0 & 74.3 \\
\hline & Near-mature forest land & 14 & 74 & 30 & 867 & 151 & 0 & 23 & 0 & 0 & 74.8 \\
\hline & Other stumpages & 0 & 0 & 1 & 5 & 71 & 0 & 0 & 0 & 0 & 92.2 \\
\hline & Water & 0 & 0 & 0 & 0 & 0 & 595 & 0 & 0 & 0 & 100.0 \\
\hline & Building land & 5 & 13 & 2 & 83 & 152 & 1 & 2326 & 4 & 3 & 89.8 \\
\hline & Wheat tillage land & 37 & 13 & 5 & 3 & 1 & 0 & 0 & 1049 & 1 & 94.6 \\
\hline & Corn stubble land & 21 & 2 & 23 & 6 & 0 & 0 & 2 & 0 & 1010 & 94.9 \\
\hline & UA (\%) & 94.3 & 43.6 & 87.2 & 75.7 & 18.9 & 99.8 & 98.7 & 94.3 & 99.5 & \\
\hline
\end{tabular}

Note: OA is 85.7 ; Kap is 0.83 . 
Table 6. The confusion matrix of classification results from polarimetric features combined with texture and coherence features.

\begin{tabular}{|c|c|c|c|c|c|c|c|c|c|c|c|}
\hline & & \multicolumn{9}{|c|}{ Classification image } & \multirow[b]{2}{*}{ PA $(\%)$} \\
\hline & & $\begin{array}{l}\text { Afforested } \\
\text { Land }\end{array}$ & $\begin{array}{c}\text { Young } \\
\text { Forest } \\
\text { Land }\end{array}$ & $\begin{array}{c}\text { Medium } \\
\text { Forest } \\
\text { Land }\end{array}$ & $\begin{array}{l}\text { Near-Mature } \\
\text { Forest } \\
\text { Land }\end{array}$ & $\begin{array}{c}\text { Other } \\
\text { Stumpages }\end{array}$ & Water & $\begin{array}{l}\text { Building } \\
\text { Land }\end{array}$ & $\begin{array}{c}\text { Wheat } \\
\text { Tillage } \\
\text { Land }\end{array}$ & $\begin{array}{c}\text { Corn } \\
\text { Stubble } \\
\text { Land }\end{array}$ & \\
\hline \multirow{10}{*}{$\begin{array}{c}\text { Reference } \\
\text { data }\end{array}$} & Afforested land & 2879 & 66 & 2 & 15 & 1 & 0 & 1 & 95 & 11 & 93.8 \\
\hline & Young forest land & 0 & 762 & 45 & 102 & 0 & 0 & 0 & 0 & 0 & 83.8 \\
\hline & Medium forest land & 0 & 299 & 2178 & 59 & 0 & 0 & 0 & 0 & 0 & 85.9 \\
\hline & Near-mature forest land & 1 & 74 & 27 & 895 & 158 & 0 & 3 & 1 & 0 & 77.2 \\
\hline & Other stumpages & 0 & 2 & 0 & 3 & 72 & 0 & 0 & 0 & 0 & 93.5 \\
\hline & Water & 0 & 0 & 0 & 0 & 0 & 595 & 0 & 0 & 0 & 100.0 \\
\hline & Building land & 33 & 0 & 0 & 30 & 29 & 0 & 2459 & 28 & 10 & 95.0 \\
\hline & Wheat tillage land & 44 & 4 & 0 & 1 & 8 & 0 & 1 & 1047 & 4 & 94.4 \\
\hline & Corn stubble land & 25 & 0 & 0 & 0 & 0 & 0 & 7 & 2 & 1030 & 96.8 \\
\hline & UA (\%) & 96.5 & 63.1 & 96.7 & 81.0 & 26.9 & 100.0 & 99.5 & 89.3 & 97.6 & \\
\hline
\end{tabular}

Note: OA is $90.9 ;$ Kap is 0.89 . 
The calculation of PA is as follows:

$$
P A_{i}=P_{i i} / P_{i+}
$$

where $i$ is the class of test pixels, $P A_{i}$ is the producer's accuracy of class $i, P_{i+}$ is the number of pixels of class $i$, and $P_{i i}$ is the number of pixels of class $i$ classified correctly.

The following equation is used to calculate UA:

$$
U A_{j}=P_{j j} / P_{+j}
$$

where $j$ is the class of classified pixels, $U A_{j}$ is the user's accuracy of class $j, P_{+j}$ is the number of pixels of class $j$, and $P_{j j}$ is the number of pixels of class $j$ classified correctly.

The calculation of OA is as follows:

$$
O A=\sum_{k=1}^{n} P_{k k} / P
$$

where $k$ is the class of test pixels and classified pixels, $O A$ is the overall accuracy, $P$ is the sum of test pixels, and $P_{k k}$ is the number of pixels of class $k$ classified correctly.

The following equation is used to calculate Kap:

$$
\text { Kap }=\left(P \sum_{i=1}^{n} P_{i i}-\sum_{i=1}^{n} P_{i+} \sum_{j=1}^{n} P_{+j}\right) /\left(P^{2}-\sum_{i=1}^{n} P_{i+} \sum_{j=1}^{n} P_{+j}\right)
$$

where Kap is Kappa coefficient, $i$ is the class of test pixels, $j$ is the class of classified pixels, $P$ is the sum of test pixels, $P_{i+}$ is the number of pixels of class $i, P_{i i}$ is the number of pixels of class $i$ classified correctly, $P_{+j}$ is the number of pixels of class $j$.

The confusion matrix was transformed into a histogram (Figure 11), which can visually show the influences of various features on classification. In Figure 11, the length of the column bar represents the proportion of each class with regard to total samples. In Figure 11a, the misclassification of forest types is evident, especially between the young forest land and medium forest land. These have a similar structure caused by the characteristics of the artificial forest. The proportion of misclassification of the non-forest types is lower than that of the forest land. This indicates that polarimetric features are suitable for distinguishing the types with obviously different structures, which supports the conclusion derived from Figure 5. By adding texture information to polarimetric features, the afforested land and building (Figure 11b) were better separated due to the unique features of their structure.

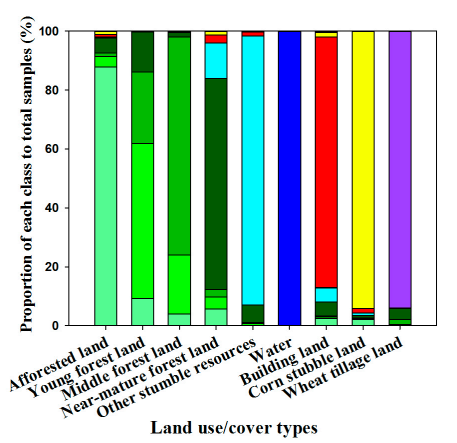

(a) Pol

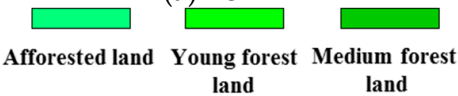

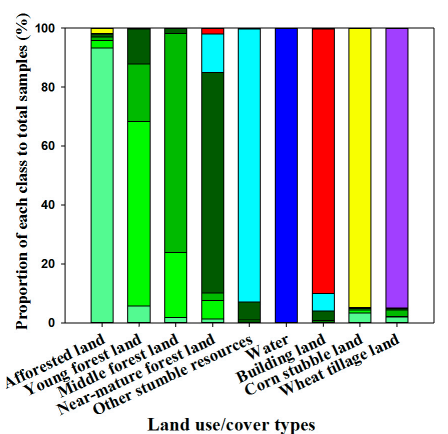

(b) Pol + RK
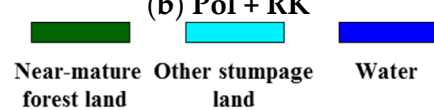

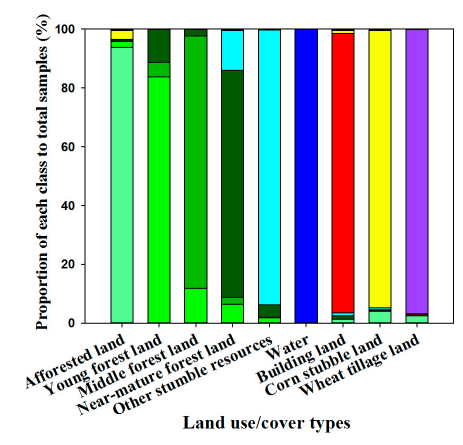

(c) Pol + RK + Coh

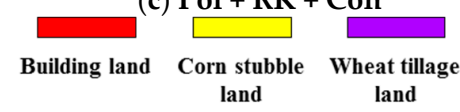

Figure 11. The proportion of each class to total samples. (a) Transformed from each line of Table 4; (b) transformed from each line of Table 5; (c) transformed from each line of Table 6. 
Combining polarimetric features and texture features can separate several non-forest types and particular forest types. However, young forest land and medium forest land cannot be distinguished perfectly due to their similarity in structure. Previous studies have shown that interferometry is sensitive to topography, vertical structure, and density of the scattering media. The interferometric decorrelation in volumetric media has been recognized as an opportunity to measure vegetation depth and extinction [47-50]. The scattering center of C-band SAR generally is located in the canopy for the closed forest, which is the main media of volume decorrelation. For a lower canopy density, the scattering center will move downwards from the canopy and the volume decorrelation of canopy will be reduced. This is a very clear example that the coherence of afforested land is higher because the scattering center is close to the ground. Nonetheless, there are differences in canopy density between young forest land and medium forest land, which influences the coherence of the C-band data. Compared to that of Figure 11a,b, the separation between young forest land and medium forest land improved with the introduced coherence features (Figure 11c). Additionally, the classification accuracy of other forest types also has been improved.

Moreover, the classification results were further evaluated using Z-score, which was calculated (shown in Table 7) based on Tables 4-6 using Equation (13):

$$
z_{i}=\frac{P_{i i}-\mu_{i}}{\sigma_{i}}
$$

where $i$ is the class of test pixels, $Z_{i}$ is the Z-score of class $i, P_{i i}$ is the number of pixels of class $i$ classified correctly, $\mu_{i}$ is the mean value of class $i$, and $\sigma_{i}$ is the standard deviation of class $i$.

Table 7. The Z-score of three classification results.

\begin{tabular}{cccc}
\hline & Pol & Pol + RK & Pol + RK + Coh \\
\hline Afforested land & 2.6621 & 2.6656 & 2.6650 \\
Young forest land & 2.3419 & 2.5111 & 2.6407 \\
Medium forest land & 2.5717 & 2.5525 & 2.6417 \\
Near-mature forest land & 2.6332 & 2.6258 & 2.6224 \\
Other stumpages & 2.6626 & 2.6602 & 2.6638 \\
Water & 2.6667 & 2.6667 & 2.6667 \\
Building land & 2.6609 & 2.6605 & 2.6663 \\
Wheat tillage land & 2.6660 & 2.6651 & 2.6645 \\
Corn stubble land & 2.6646 & 2.6657 & 2.6659 \\
\hline
\end{tabular}

Note: Pol is the classification result from polarimetric features; Pol + RK is the classification results from polarimetric features combined with texture features; Pol $+\mathrm{RK}+\mathrm{Coh}$ is the classification results from polarimetric features combined with texture and coherence features.

Figure 12 was transformed from Table 7 to visually show the influences of various features on classification. In Figure 12, the classification accuracy of young forest land and medium forest land obviously improved with the integration of texture and coherence features, which is consistent with the confusion matrixes (Tables 4-6).

Various features have been analyzed the separability for land use/cover types and further compared this by classification results. It is shown that the non-forest types can be discriminated only using Freeman-Durden decomposition parameters $\left(P_{\mathrm{d}}, P_{\mathrm{v}}\right.$, and $\left.P_{\mathrm{s}}\right)$ and Cloude-Pottier decomposition parameters $(\alpha, H$, and $A)$. For the forest growth stages, the Freeman-Durden decomposition and Cloude-Pottier parameters can play an important role in classifying forest growth stages with significant differences in characteristic structures, such as the separation between afforested land and other forest types as well as medium forest land and near-mature forest land. The $R K$ feature can further reduce misclassification between afforested land and other forest types, as well as slightly mitigate the confusion between young forest land and medium forest land. Furthermore, $\gamma_{o p t \_1}, \gamma_{\text {opt } \_2}$, and $A_{2}$ can obviously separate the young forest land and medium forest land. 


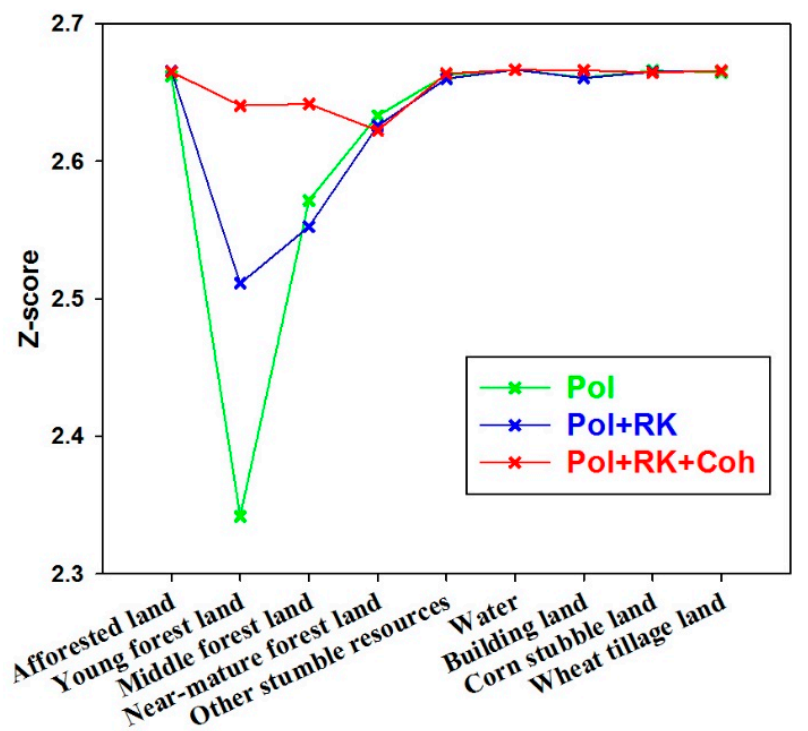

Figure 12. The Z-score of three classification results. Pol is the classification result from polarimetric features; Pol + RK is the classification results from polarimetric features combined with texture features; $\mathrm{Pol}+\mathrm{RK}+\mathrm{Coh}$ is the classification results from polarimetric features combined with texture and coherence features.

\section{Discussion}

This study suggests that PolInSAR data are of value in land use/cover classification, especially in distinguishing forest growth stage. This study also address confusion of forest growth stages by incorporating polarimetric, texture, and coherence features based on an SVM classification. Forest plantations are characterized as a single tree species and uniform distribution. However, the principal differences between young forest land, medium forest land, and near-mature forest land exist in the tree canopy, which is the main scattering media for the C-band SAR. As can be seen in Figure 11a, the afforested land and other forest types were slightly confused, while the young forest land and medium forest land were substantially confused. This may result from the canopy structure in young forest land that is similar to that in medium forest land. With the texture information added, although the confusions between afforested land and other forest types were obviously reduced, the confusions between the young forest land and the medium forest land were slightly reduced, also due to the similar spatial heterogeneity. Consequently, coherence features have been introduced to discriminate young forest land and medium forest land due to the interferometry sensitivity to volume decorrelation caused by a slight structure difference. Moreover, the afforested land and other forest types were almost separated. The difference in coherence is small between the medium forest land and near-mature forest land, probably because the coherence of these two classes are saturated in C-band within a closed canopy. Thus, it is difficult to use coherence features to distinguish these types, although $\alpha$ had been proved to be effective in discriminating these types (Figure 5e). For non-forest types, the misclassification of building land and trees mixed in building land was improved in this study by using texture and coherence features. Overall, this study presents the necessity of integrating polarimetric, texture, and coherence features in land use/cover classification.

However, parts of the near-mature forest land, such as the road shelter forest (distribution along a road with several rows), usually present the features of individual trees, which were misclassified to other stumpages. Therefore, the misclassification between the near-mature forest land and other stumpages exists in this test site. In the future, more features or algorithms would be employed to cope with the problems.

Compared to PolSAR data, PolInSAR contained more comprehensive and detailed information, including the topography, vertical structure, and density of the scattering media. PolInSAR 
has been recognized as the tool with the most potential for land use/cover classification [23,27]. However, few studies have incorporated polarimetric, texture, and coherence information obtained from PolInSAR data for a detailed classification of forest types. Other polarimetric features (e.g., coherency matrix and intensity) and decomposition methods will be analyzed in future studies to reduce misclassification.

Strictly speaking, the validation data should be collected randomly from an existing classification product to cover the entire study area. Due to the working conditions, we collected some true ground data through field work and collected more samples, including SAR and Google Earth images. Although the validation data are not randomized and not representative of the entire study area, they are representative of the majority of types, as each type has a homogeneous and even distribution. A stricter validation data collection method should be adopted in future studies. In this study, the AOIs of each type were only randomly divided into training and validation data once. To enhance the robustness of conclusions, the simple random sampling method should be used to select two-thirds of the AOIs as training data, with the remaining AOIs used as validation data. This dividing procedure should then be repeated several times.

In this paper, we focused on analyzing the capability of various features on the classification of forest growth stages, so the histogram analysis method was implemented to understand the effect of SAR scattering properties on forest growth stage types visually. Unfortunately, the automatic and accurate feature selections, such as SVM Recursive Feature Elimination (SVM-RFE) or random forest machine learning algorithm, were not used. Additionally, the classification results were obtained with the help of SVM in ENVI 4.8 software, with no parameter optimization having been carried out; a k-fold cross validation with a grid search should be implemented. In a word, various questions about the classifier, including parameter optimization and variable selection algorithm, will be improved in future studies.

The capabilities of some features derived from airborne SAR data for the classification of forest stages have thus been shown. We need to further study whether these features from space-borne SAR data are equally effective, as this is significant for monitoring large-scale forest plantations.

\section{Conclusions}

This study proposes a strategy for the classification of forest growth stages using an SVM based on C-band PolInSAR data obtained from the Chinese MSJosSAR system. It integrates several features, including polarimetric features based on polarimetric decomposition, texture features using non-Gaussian modeling, and coherence features obtained from coherence optimization theory. Following this, the capabilities of these features for distinguishing land use/cover types were analyzed.

For non-forest types (water, building land, wheat tillage land, and corn stubble land), it was feasible to distinguish them using polarimetric features because of their obvious structural variations. Texture and coherence features could be used to improve classification among the types, which have differences in spatial heterogeneity and structure, such as building land and forest land.

The forest is characterized by unique scattering properties that are different from non-forest areas, so it can be discriminated using polarimetric information. For one species, different forest growth stages correspond to various structural characteristics (canopy density and tree height). Polarimetric information can play an important role for forest growth stages, with significant differences in structural characteristics (afforested land and other forest types), although it is not suitable for similar structural characteristics (young forest land and medium forest land). Fortunately, texture and coherence are helpful for discriminating forest growth stages with structural characteristics due to their sensitivity to spatial characteristics and volume decorrelation, respectively. Overall, the integration of polarimetric, texture, and coherence features improves classification accuracy in addition to providing useful insights into forest classification and further sustainable management. 
Acknowledgments: This research was financially supported by Major National Science and Technology Infrastructure Program (Chinese Aeronautic Remote Sensing System). The authors would like to thank three reviewers for their helpful constructive comments that improved this research.

Author Contributions: Q.F. is the principal author of this manuscript, having written the majority of the manuscript, and contributed at all phases of the investigation. L.Z., X.L., and E.C. contributed to the interpretation of the methods and provided suggestions regarding the structure. L.Z. and Y.Z. contributed to the data processing.

Conflicts of Interest: The authors declare no conflicts of interest.

\section{References}

1. West, P. Tree and Forest Measurement, 2nd ed.; Springer: Berlin/Heidelberg, Germany, 2009.

2. Lucas, R.M.; Clewley, D.; Accad, A. Mapping forest growth and degradation stage in the brigalow belt bioregion of australia through integration of alos palsar and landsat-derived foliage projective cover data. Remote Sens. Environ. 2014, 155, 42-57. [CrossRef]

3. Galvao, L.S.; Ponzoni, F.J.; Liesenberg, V.; Santos, J.R.D. Possibilities of discriminating tropical secondary succession in Amazonia using hyperspectral and multiangular CHRIS/PROBA data. Int. J. Appl. Earth Obs. Geoinf. 2009, 11, 8-14. [CrossRef]

4. Wijaya, A.; Reddy Marpu, P.; Gloaguen, R. Discrimination of peatlands in tropical swamp forests using dual-polarimetric SAR and Landsat ETM data. Int. J. Image Data Fusion 2010, 1, 257-270. [CrossRef]

5. Kuplich, T.M. Classifying regenerating forest stages in Amazonia using remotely sensed images and a neural network. For. Ecol. Manag. 2006, 234, 1-9. [CrossRef]

6. Xu, L.Y.; Li, S.Q.; Deng, Y.K. Improved Three-stage Algorithm of Forest Height Retrieval with PolInSAR. J. Radars 2014, 3, 28-34.

7. Xu, F.; Wang, H.P.; Jin, Y.Q. Deep Learning as Applied in SAR Target Recognition and Terrain Classification. J. Radars 2017, 6, 136-148.

8. Tian, W.; Xu, X.; Bian, X.L. Applications of Environmental Remote Sensing by HJ-1C SAR Imageries. J. Radars 2014, 3, 339-351.

9. Simard, M.; Saatchi, S.S.; De Grandi, G. The use of decision tree and multiscale texture for classification of JERS-1 SAR data over tropical forest. IEEE Trans. Geosci. Remote Sens. 2000, 38, 2310-2321. [CrossRef]

10. Ningthoujam, R.K.; Tansey, K.; Balzter, H.; Morrison, K.; Johnson, S.C.M.; Gerard, F.; George, C.; Burbidge, G.; Doody, S.; Veck, N.; et al. Mapping Forest Cover and Forest Cover Change with Airborne S-Band Radar. Remote Sens. 2016, 8, 577. [CrossRef]

11. Rahman, M.M.; Sumantyo, J.T.S. Erratum to: Mapping Tropical forest cover and deforestation using Synthetic Aperture Radar (SAR) Images. Appl. Geomat. 2010, 2, 197. [CrossRef]

12. Lehmann, E.A.; Caccetta, P.A.; Zhou, Z.; McNeill, S.J.; Wu, X.; Mitchell, A.L. Joint processing of Landsat and ALOS-PALSAR data for forest mapping and monitoring. IEEE Trans. Geosci. Remote Sens. 2012, 50, 55-67. [CrossRef]

13. Longepe, N.; Rakwatin, P.; Isoguchi, O.; Shimada, M.; Uryu, Y.; Yulianto, K. Assessment of ALOS PALSAR $50 \mathrm{~m}$ orthorectified FBD data for regional land cover classification by Support Vector Machines. IEEE Trans. Geosci. Remote Sens. 2011, 49, 2135-2150. [CrossRef]

14. Minchella, A.; Del Frate, F.; Capogna, F.; Anselmi, S.; Manes, F. Use of multitemporal SAR data for the monitoring of the vegetation recovery in burned areas. Remote Sens. Environ. 2009, 113, 588-597. [CrossRef]

15. Lee, J.S.; Papathanassiou, K.P.; Hajnsek, I.; Mette, T. Applying polarimetric SAR interferometric data for forest classification. In Proceedings of the 2005 IEEE International Geoscience and Remote Sensing Symposium (IGARSS 2005), Seoul, Korea, 29 July 2005; Volume 7, pp. 4848-4851.

16. Hoekman, D.; Quinones, M. Biophysical forest type characterization in the Colombian Amazon by airborne polarimetric SAR. IEEE Trans. Geosci. Remote Sens. 2002, 40, 1288-1300. [CrossRef]

17. Proisy, C.; Mougin, E.; Dufrene, E.; Dantec, V.L. Monitoring seasonal changes of a mixed temperature forest using ERS SAR observations. IEEE Trans. Geosci. Remote Sens. 2000, 38, 540-552. [CrossRef]

18. Touzi, R.; Landry, R.; Charbonneau, F.J. Forest type discrimination using calibrated C-band polarimetric SAR data. Can. J. Remote Sens. 2004, 30, 543-551. [CrossRef]

19. Maghsoudi, Y.; Collins, M.J.; Leckie, D.G. Radarsat-2 Polarimetric SAR Data for Boreal Forest Classification Using SVM and a Wrapper Feature Selector. IEEE J. Sel. Top. Appl. Earth Obs. Remote Sens. 2013, 6, 1531-1538. [CrossRef] 
20. Cloude, S.R.; Pottier, E. A review of target decomposition theorems in radar polarimetry. IEEE Trans. Geosci. Remote Sens. 1996, 34, 498-518. [CrossRef]

21. Freeman, A.; Durden, S.L. A three-component scattering model for polarimetric SAR data. IEEE Trans. Geosci. Remote Sens. 1998, 36, 963-973. [CrossRef]

22. Chinatsu, Y.; Manabu, W.; Genya, S. Polarimetric Decomposition Analysis of ALOS PALSAR Observation Data before and after a Landslide Event. Remote Sens. 2012, 4, 2314-2328.

23. Gama, F.F.; Dos Santos, J.R.; Mura, J.C. Eucalyptus biomass and volume estimation using interferometric and polarimetric SAR data. Remote Sens. 2010, 2, 939-956. [CrossRef]

24. Lee, J.S.; Grunes, M.R.; Ainsworth, T.L.; Du, L.J.; Schuler, D.L.; Cloude, S.R. Unsupervised classification using polarimetric decomposition and the complex Wishart classifier. IEEE Trans. Geosci. Remote Sens. 1999, 37, 2249-2258.

25. Ferro-Famil, L.; Pottier, E.; Lee, J.S. Unsupervised classification of multifrequency and fully polarimetric SAR images based on the H/A/Alpha-Wishart classifier. IEEE Trans. Geosci. Remote Sens. 2001, 39, 2332-2342. [CrossRef]

26. Lee, J.S.; Grunes, M.R.; Pottier, E.; Ferro-Famil, L. Unsupervised terrain classification preserving scattering characteristics. IEEE Trans. Geosci. Remote Sens. 2004, 42, 722-731.

27. Ferro Famil, L.; Pottier, E.; Lee, J.S. Unsupervised classification of natural scenes from polarimetric interferometric SAR data. In Proceedings of the IEEE 2001 International Geoscience and Remote Sensing Symposium (IGARSS 2001), Sydney, Australia, 9-13 July 2001; Volume 6, pp. 2715-2717.

28. Ferro-Famil, L.; Kugler, F.; Potier, E.; Lee, J.S. Forest mapping and classification at L-Band using Pol-InSAR optimal coherence set statistics. In Proceedings of the European Conference on Synthetic Aperture Radar, Dresden, Germany, 16-18 May 2006; pp. 1-4.

29. Lu, D.; Batistella, M.; Moran, E. Land-Cover Classification in the Brazilian Amazon with the Integration of Landsat ETM+ and RADARSAT Data. Int. J. Remote Sens. 2007, 28, 5447-5459. [CrossRef]

30. Laurin, G.V.; Liesenberg, V.; Chen, Q.; Guerriero, L.; Frate, F.D.; Bartolini, A.; Coomes, D.; Wilebore, B.; Lindsell, J.; Valentini, R. Optical and SAR sensor synergies for forest and land cover mapping in a tropical site in west Africa. Int. J. Appl. Earth Obs. Geoinf. 2013, 21, 7-16. [CrossRef]

31. Liu, G.; Li, L.; Gong, H.; Jin, Q.W.; Li, X.W.; Song, R.; Chen, Y.; Chen, Y.; He, C.X.; Huang, Y.Q.; et al. Multisource Remote Sensing Imagery Fusion Scheme Based on Bidimensional Empirical Mode Decomposition (BEMD) and Its Application to the Extraction of Bamboo Forest. Remote Sens. 2017, 9, 19. [CrossRef]

32. Li, G.; Lu, D.; Moran, E.; Dutra, L.; Batistella, M. A Comparative analysis of ALOS PALSAR L-band and RADARSAT-2 C-band data for land-cover classification in a tropical moist region. ISPRS J. Photogramm. Remote Sens. 2012, 70, 26-38. [CrossRef]

33. Robinson, C.; Saatchi, S.S.; Neumann, M.; Gillespie, T. Impacts of spatial variability on aboveground biomass estimation from L-Band radar in a temperate forest. Remote Sens. 2013, 5, 1001-1023. [CrossRef]

34. Vapnik, V. Estimation of Dependences Based on Empirical Data; Springer: New York, NY, USA, 2006.

35. Lin, H.T.; Lin, C.J. A study on sigmoid kernels for SVM and the training of non-PSD kernels by SMO-type methods. Neural Comput. 2003, 27, 15-23.

36. Merchant, M.A.; Adams, J.R.; Berg, A.A.; Baltzer, J.L.; Quinton, W.L.; Chasmer, L.E. Contributions of c-band SAR data and polarimetric decompositions to subarctic boreal peatland mapping. IEEE J. Sel. Top. Appl. Earth Obs. Remote Sens. 2017, 10, 1467-1482. [CrossRef]

37. Doulgeris, A. Non-Gaussian Statistical Analysis of Polarimetric Synthetic Aperture Radar Images. Ph.D. Thesis, University of Tromsø (UIT), Tromsø, Norway, 2011.

38. Papathanassiou, K.P.; Cloude, S.R. Single-baseline polarimetric SAR interferometry. IEEE Trans. Geosci. Remote Sens. 2001, 39, 2352-2363. [CrossRef]

39. Tison, C.; Pourthié, N.; Souyris, J.C. Target recognition in SAR images with support vector machine (SVM). In Proceedings of the 2007 IEEE International Geoscience and Remote Sensing Symposium (IGARSS 2007), Barcelona, Spain, 23-28 July 2007; pp. 456-459.

40. Mercier, G.; Girard-Ardhuin, F. Unsupervised oil slick detection by SAR imagery using kernel expansion. In Proceedings of the 2005 IEEE International Geoscience and Remote Sensing Symposium (IGARSS 2005), Seoul, Korea, 29 July 2005; Volume 1, pp. 494-497. 
41. Attarchi, S.; Gloaguen, R. Classifying Complex Mountainous Forests with L-Band SAR and Landsat Data Integration: A Comparison among Different Machine Learning Methods in the Hyrcanian Forest. Remote Sens. 2014, 6, 3624-3647. [CrossRef]

42. Burges, C.J. A tutorial on support vector machines for pattern recognition. In Data Mining Knowledge Discovery; Fayyad, U., Ed.; Kluwer: Norwell, MA, USA, 1998.

43. Auer, S.; Gisinger, C.; Tao, J. Characterization of facade regularities in high-resolution SAR images. IEEE Trans. Geosci. Remote Sens. 2015, 53, 2727-2737. [CrossRef]

44. Gaveau, D.L.A.; Balzter, H.; Plummer, S. Forest woody biomass classification with satellite-based radar coherence over 900,000 km², in Central Siberia. For. Ecol. Manag. 2003, 174, 65-75. [CrossRef]

45. Askne, J.I.H.; Santoro, M. Multitemporal repeat pass SAR interferometry of boreal forests. IEEE Trans. Geosci. Remote Sens. 2005, 43, 1219-1228. [CrossRef]

46. Cartus, O.; Santoro, M.; Schmullius, C. Creation of large area forest biomass maps for Northeast China using ERS-1/2 tandem coherence. In Proceedings of the Dragon 1 Programme Final Results 2004-2007, Beijing, China, 21-25 April 2008; Volume 1, pp. 2004-2007.

47. Rosen, P.A.; Hensley, S.; Joughin, I.R.; Li, F.K.; Madsen, S.N.; Rodriguez, E.; Goldstein, R.M. Synthetic aperture radar interferometry. Proc. IEEE 2000, 88, 333-382. [CrossRef]

48. Bamler, R.; Hartl, P. Synthetic aperture radar interferometry. Inverse Probl. 1998, 14, R1-R54. [CrossRef]

49. Treuhaft, R.N.; Madsen, S.N.; Moghaddam, M.; van Zyl, J.J. Vegetation characteristics and underlying topography from interferometric radar. Radio Sci. 1996, 31, 1449-1485. [CrossRef]

50. Askne, J.I.H.; Dammert, P.B.G.; Ulander, L.M.H.; Smith, G. C-band repeat-pass interferometric SAR observations of the forest. IEEE Trans. Geosci. Remote Sens. 1997, 35, 25-35. [CrossRef]

(C) 2017 by the authors. Licensee MDPI, Basel, Switzerland. This article is an open access article distributed under the terms and conditions of the Creative Commons Attribution (CC BY) license (http:/ / creativecommons.org/licenses/by/4.0/). 